\title{
Coupled carbon-water exchange of the Amazon rain forest, I. Model description, parameterization and sensitivity analysis
}

\author{
E. Simon ${ }^{1}$, F. X. Meixner ${ }^{1}$, L. Ganzeveld ${ }^{2}$, and J. Kesselmeier ${ }^{1}$ \\ ${ }^{1}$ Biogeochemistry Dept., Max Planck Institute for Chemistry, Mainz, Germany \\ ${ }^{2}$ Atmospheric Chem. Dept., Max Planck Institute for Chemistry, Mainz, Germany \\ Received: 24 February 2005 - Published in Biogeosciences Discussions: 7 April 2005 \\ Revised: 15 August 2005 - Accepted: 26 August 2005 - Published: 8 September 2005
}

\begin{abstract}
Detailed one-dimensional multilayer biosphereatmosphere models, also referred to as CANVEG models, are used for more than a decade to describe coupled watercarbon exchange between the terrestrial vegetation and the lower atmosphere. Within the present study, a modified CANVEG scheme is described. A generic parameterization and characterization of biophysical properties of Amazon rain forest canopies is inferred using available field measurements of canopy structure, in-canopy profiles of horizontal wind speed and radiation, canopy albedo, soil heat flux and soil respiration, photosynthetic capacity and leaf nitrogen as well as leaf level enclosure measurements made on sunlit and shaded branches of several Amazonian tree species during the wet and dry season. The sensitivity of calculated canopy energy and $\mathrm{CO}_{2}$ fluxes to the uncertainty of individual parameter values is assessed. In the companion paper, the predicted seasonal exchange of energy, $\mathrm{CO}_{2}$, ozone and isoprene is compared to observations.

A bi-modal distribution of leaf area density with a total leaf area index of 6 is inferred from several observations in Amazonia. Predicted light attenuation within the canopy agrees reasonably well with observations made at different field sites. A comparison of predicted and observed canopy albedo shows a high model sensitivity to the leaf optical parameters for near-infrared short-wave radiation (NIR). The predictions agree much better with observations when the leaf reflectance and transmission coefficients for NIR are reduced by $25-40 \%$. Available vertical distributions of photosynthetic capacity and leaf nitrogen concentration suggest a low but significant light acclimation of the rain forest canopy that scales nearly linearly with accumulated leaf area.

Evaluation of the biochemical leaf model, using the enclosure measurements, showed that recommended parameter values describing the photosynthetic light response, have
\end{abstract}

Correspondence to: E. Simon

(simon@mpch-mainz.mpg.de) to be optimized. Otherwise, predicted net assimilation is overestimated by $30-50 \%$. Two stomatal models have been tested, which apply a well established semi-empirical relationship between stomatal conductance and net assimilation. Both models differ in the way they describe the influence of humidity on stomatal response. However, they show a very similar performance within the range of observed environmental conditions. The agreement between predicted and observed stomatal conductance rates is reasonable. In general, the leaf level data suggests seasonal physiological changes, which can be reproduced reasonably well by assuming increased stomatal conductance rates during the wet season, and decreased assimilation rates during the dry season.

The sensitivity of the predicted canopy fluxes of energy and $\mathrm{CO}_{2}$ to the parameterization of canopy structure, the leaf optical parameters, and the scaling of photosynthetic parameters is relatively low (1-12\%), with respect to parameter uncertainty. In contrast, modifying leaf model parameters within their uncertainty range results in much larger changes of the predicted canopy net fluxes (5-35\%).

\section{Introduction}

Within the last decades, our understanding of atmospheric and biogeochemical processes has substantially improved. Sophisticated model schemes have been developed to describe surface exchange of trace gases and their fate in the atmosphere. For the terrestrial vegetation detailed onedimensional multilayer biosphere-atmosphere models, also referred to as CANVEG models, are now available for more than a decade (Baldocchi, 1992; Baldocchi and Meyers, 1998). As shown in Fig. 1, these models have evolved from simple big leaf and two layer models (Deardorff, 1978; Noilhan and Planton, 1989). Although the simple models have become very useful by including detailed descriptions of soil moisture status (Dickinson et al., 1993), radiation

(C) 2005 Author(s). This work is licensed under a Creative Commons License. 

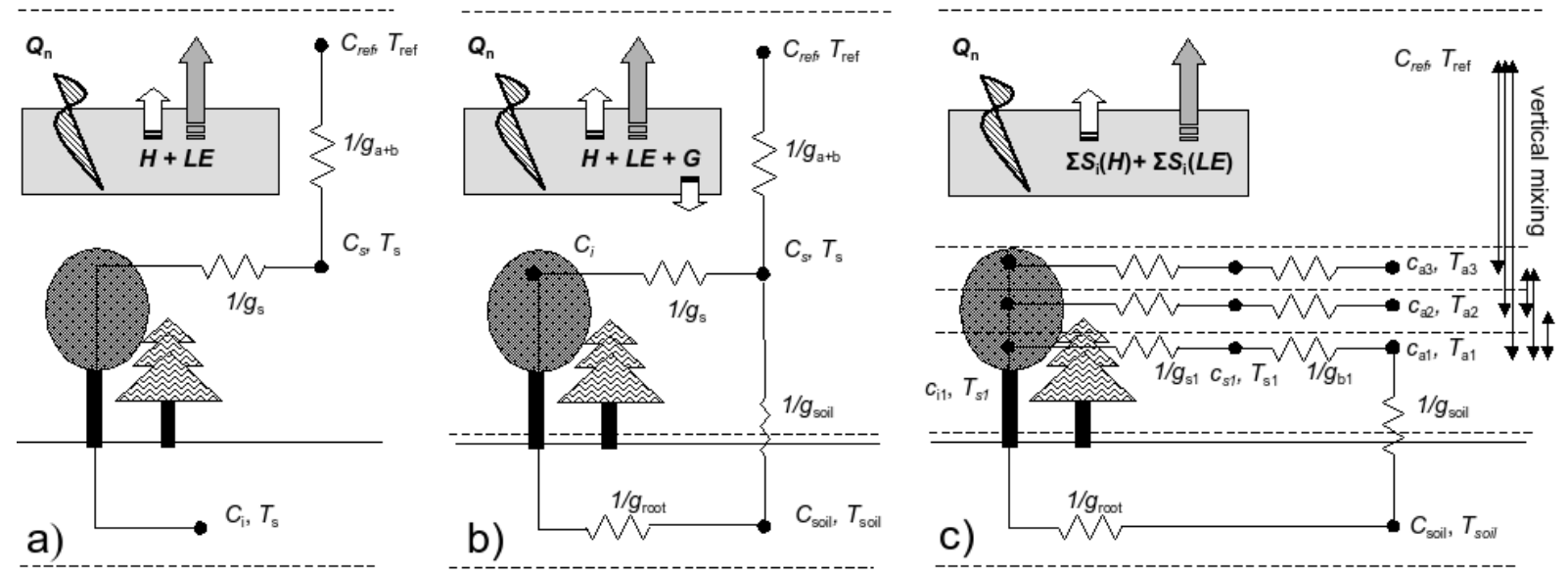

Fig. 1. Calculation of the surface energy balance in three canopy parameterization schemes with increasing complexity: (a) Single-layer scheme assuming $T_{\text {soil }}=T_{S}$ with $Q_{n}=H+L E$. (b) Two-layer scheme (soil + big leaf) with $Q_{n}=H+L E+G$. (c) Multi-layer CANVEG scheme (soil +3 vegetation layers +1 layer above the canopy) with $Q_{n}=\sum_{i} S_{i}(H)+S_{i}(L E)$. Symbols represent temperature of the soil $\left(T_{\text {soil }}\right)$, the canopy air $\left(T_{a}\right)$, the foliage $\left(T_{S}\right)$, and the air above the canopy $\left(T_{\text {ref }}\right)$, available net radiation $\left(Q_{n}\right)$, sensible $(H)$ and latent $(L E)$ heat, the soil heat flux $(G)$, and the stomatal $\left(g_{s}\right)$, leaf boundary-layer $\left(g_{b}\right)$, aerodynamic $\left(g_{a}\right)$, bulk soil surface $\left(g_{\text {soil }}\right)$ and root $\left(g_{\text {root }}\right)$ conductance (see also Garrat, 1992, note that $g_{a}, g_{\text {root }}$ are not included in the list of symbols).

reflectance and photosynthesis (Sellers et al., 1992, 1996) and dry deposition (Ganzeveld and Lelieveld, 1995), they are mostly empirical, which means that biophysical model parameters such as the bulk stomatal conductance have only a weak correspondence to the real world. In contrast, the CANVEG scheme integrates the exchange of trace gases and energy "bottom-up" from the leaf to the canopy level (Jarvis, 1993; Leuning et al., 1995). Therefore biophysical model parameters such as stomatal conductance correspond to biophysical leaf parameters and are calculated by a well-established mechanistic approach, which couples $\mathrm{CO}_{2}$ exchange to transpiration and the leaf energy balance (Farquhar et al., 1980; Caemmerer and Farquhar, 1981; Ball et al., 1987; Leuning, 1990; Collatz et al., 1991; Lloyd, 1991; Collatz et al., 1992; Leuning, 1995). Most of the information required for model parameterization can be derived from eco-physiological principles, which state that photosynthetic capacity and maximum stomatal conductance are related to leaf nitrogen content, which again is determined by the light environment of the leaf and the nitrogen availability for the whole plant (Field, 1983; Hirose et al., 1988; Wullschleger, 1993; Schulze et al., 1994; Leuning et al., 1995). Furthermore, CANVEG models apply Lagrangian dispersion theory (Raupach, 1989) to calculate vertical scalar profiles within the free canopy air space. In contrast to multilayer models which apply classical K-theory, the Lagrangian approach accounts also for counter-gradient transfer and non-local dispersion across multiple layers (Raupach, 1987; Katul and Albertson, 1999; Lai et al., 2000a; Wilson et al., 2003).

Compared to a big leaf approach, the detailed description of canopy processes in CANVEG allows diagnostic applications to study some feed-backs between biogeochemical and atmospheric processes (e.g. $\mathrm{CO}_{2}$ fertilization) and to separate the influence of environmental and eco-physiological factors on trace gas exchange. Despite large data pools, being available from long-term and intensive regional studies (Grace et al., 1995; Gash et al., 1996; Sellers et al., 1997; Seufert et al., 1997; Halldin et al., 1999; Andreae et al., 2002; Gu and Baldocchi, 2002; Falge et al., 2002) for model parameterization, evaluation and application, only agricultural crops, and broad-leaved and coniferous forests in temperate regions have been investigated within a CANVEG model frame work (see Baldocchi and Harley, 1995; Baldocchi and Meyers, 1998; Baldocchi and Wilson, 2001; Lai et al., 2000a,b; Katul et al., 2003; Baldocchi and Bowling, 2003).

In the present study, we applied a modified CANVEG scheme to Amazon rain forest. Because of its large area of about $5 \times 10^{6} \mathrm{~km}^{2}$ (Laurance, 2000) and its all-seasonal high biological activity the Amazon rain forest plays an important role in the global climate system. Despite its vast bio-diversity, the non-flooded areas are relatively homogeneously covered by lowland deciduous tropical rain forest ("terra firma"). Since the region is located in the inner tropics, the day length, mean temperature and daily integrated solar radiation are relatively constant. The scheme we developed is mainly a synthesis of the original CANVEG model (Baldocchi and Meyers, 1998), the Lagrangian dispersion approach proposed by Raupach (1989) and the leaf-to-canopy integration scheme described by Leuning et al. (1995). As far as we know there exist no further studies that explicitly model the coupled exchange of $\mathrm{CO}_{2}$ and energy of Amazon rain forest canopies including the Lagrangian approach for turbulent exchange: There is the big leaf approach of Lloyd et al. (1995), focusing mainly on $\mathrm{CO}_{2}$, and the multilayer 
soil-plant-atmosphere model of Williams et al. (1998), coupling the water flow from the soil to the atmosphere with $\mathrm{C}$ Fixation by including a detailed soil module. However, both models differ significantly from the CANVEG type since temperature and scalar gradients inside the canopy are neglected (no transport model included). Furthermore, since those model developments many new site specific data have been provided in the meantime by $\mathrm{LBA}^{1}$ campaigns, in our case especially by LBA-EUSTACH ${ }^{2}$ in 1999 (Andreae et al., 2002).

Here we present the description of the modified CANVEG model. Using informations from LBA and Pre-LBA studies, a characterization of mean canopy structure, the distribution of photosynthetic capacity and a normalized profile of horizonal wind speed is given. The subroutines to calculate the canopy radiation field and soil surface exchange as well as leaf photosynthesis and stomatal conductance, considering wet and dry season conditions, are described and evaluated. The parameterization of the Lagrangian dispersion submodel is discussed and evaluated in detail in a further study (Simon et al., 2005a). Finally, the sensitivity of predicted net fluxes to key parameter uncertainty is investigated. In a companion paper (Simon et al., 2005b), the calculated exchange of sensible and latent heat, $\mathrm{CO}_{2}$, isoprene, and ozone as well as the vertical profiles of $\mathrm{H}_{2} \mathrm{O}, \mathrm{CO}_{2}$ and ozone for the main research site of LBA-EUSTACH in Rondônia are compared to measurements made at two micrometeorological towers during the late wet and late dry season 1999.

\section{Materials and methods}

\subsection{Site description and field data}

Most of the data sets used in the present study were obtained at or around four micrometeorological towers installed at the two main forest research sites of LBA and the PreLBA study ABRACOS ${ }^{3}$. The first site is located in the federal state Rondônia in southwest Amazonia. It is part of the Reserva Biológica Jaru (RBJ) and belongs to the Instituto Brasileiro do Meio Ambiente e dos Recursos Naturais Renováveis (IBAMA). It was the main forest research site of LBA-EUSTACH in 1999 (Andreae et al., 2002). There were two parts of this campaign, EUST-I and EUST-II, coinciding with the 1999 wet-to-dry (April to May) and dry-towet (September to November) season transition periods. The second site is located $\approx 60 \mathrm{~km}$ NNW of Manaus in central Amazonia. It is accessible by a small road and part of the Reserva Biológica do Cuieiras, which belongs to the Instituto Nacional de Pesquisas da Amazônia (INPA). Hereafter,

\footnotetext{
${ }^{1}$ Large-Scale Biosphere-Atmosphere Experiment in Amazonia.

${ }^{2}$ European Studies on Trace Gases and Atmospheric Chemistry as a Contribution to LBA.

${ }^{3}$ Anglo-Brazilian Amazonian Climate Observation Study.
}

Table 1. Site and tower locations (see Andreae et al., 2002).

\begin{tabular}{|c|c|c|c|}
\hline Tower & Site & Location & Elevation \\
\hline RBJ $^{-A^{1}}$ & Jaru & $10^{\circ} 04.92^{\prime} \mathrm{S} 61^{\circ} 55.80^{\prime} \mathrm{W}$ & $147 \mathrm{~m}$ \\
\hline RBJ-B ${ }^{2}$ & Jaru & $10^{\circ} 04.70^{\prime} \mathrm{S} 61^{\circ} 56.02^{\prime} \mathrm{W}$ & $145 \mathrm{~m}$ \\
\hline $\mathrm{C} 14^{3}$ & Cuieiras & $02^{\circ} 35.35^{\prime} \mathrm{S} 60^{\circ} 06.89^{\prime} \mathrm{W}$ & $90 \mathrm{~m}$ \\
\hline $\mathrm{K} 34^{1}$ & Cuieiras & $02^{\circ} 35.55^{\prime} \mathrm{S} 60^{\circ} 12^{\prime} 46 \mathrm{~W}$ & $93 \mathrm{~m}$ \\
\hline
\end{tabular}

Height: ${ }^{1} 53 \mathrm{~m},{ }^{2} 60 \mathrm{~m},{ }^{3} 40 \mathrm{~m}$

both sites will referred to as the Jaru and Cuieiras site, respectively.

The Jaru site experiences a more marked dry season with a mean annual rainfall of $1600 \mathrm{~mm}$ compared to $2100 \mathrm{~mm}$ at the Cuieiras site (Gash et al., 1996). Both sites are characterized as terra firma with primary tropical rain forest although the dominating vegetation type differs to some extent (Grace et al., 1995; Carswell et al., 2000; Kruijt et al., 2000; Simon et al., 2005a).

Site and tower locations are listed in Table 1. More detailed site descriptions and a general overview on LBAEUSTACH is given by Andreae et al. (2002). Except the measurements of canopy structure at C14 (which is described below), all data records used in the present study have already been published and described in detail by the references given in Table 2. Therefore, we just shortly describe how these data have been applied in our analysis.

Canopy structure $\left(\Lambda_{z}\right.$, a complete list of symbols is given at the end of Sect. 4) has been measured at RBJ-A, C14, and K34 using the optical Plant Canopy Analyzer LAI-2000 (Li-Cor, Lincoln, USA). For a comparison of different methods see Eschenbach and Kappen (1996). At the C14 tower, two profiles of $\Lambda_{z}$ have been measured on 17 July 2001 under prevailing cloudy conditions. For each profile, 12 equally distributed individual measurements were performed in a concentric circle at 4, 8, 12, 16, 20, 24, 28, 32, and $40 \mathrm{~m}$ height. For the further analysis using additional observations (see Table 2) the mean values from both profiles have been used. Profiles of horizontal wind speed $u(z)$ were measured at the RBJ-A tower at 1, 11, 20.7, 31.3, 42.2 and $51.7 \mathrm{~m}$ height (Rummel, 2005). Photosynthetic active radiation $\left(Q_{P A R}\right)$ is calculated as a fixed ratio of visible radiation $\left(Q_{v}\right.$, see Sect. 2.3). For incoming photosynthetic active radiation $\left(Q_{P A R 0}\right)$, this relationship is tested using direct observations made at RBJ-A,B and K34. An empirical relationship to calculate incoming long-wave radiation (Brutsaert, 1975) is tested using measurements made at RBJ-B (Andreae et al., 2002). The predicted canopy albedo is compared to monthly mean values observed by Culf et al. (1995) and Culf et al. (1996) at RBJ-A and a second site near Manaus. The radiation attenuation sub-model is evaluated using: 
Table 2. Field data used for model parameterization and sub-model evaluation (see also Table 1).

\begin{tabular}{|c|c|c|c|c|}
\hline Sect. & Parameter & Site & Reference & Note \\
\hline 3.1 & $\Lambda_{z}$ & $\begin{array}{l}\text { near Manaus } \\
\text { near Manaus } \\
\text { Jaru (RBJ-A) } \\
\text { Cuieiras (C14) } \\
\text { Cuieiras (K34) }\end{array}$ & $\begin{array}{l}\text { Roberts et al. }(1993)^{*, 1} \\
\text { McWilliam et al. }(1993)^{*, 2} \\
\text { Simon et al. }(2005 \mathrm{a})^{\dagger, 3} \\
\text { unpublished }{ }^{\dagger, 3} \\
\text { Simon et al. }(2005 \mathrm{a})^{\dagger, 3}\end{array}$ & calibration of Eq. (31) (Table 5) \\
\hline 3.2 & $u(z)$ & Jaru (RBJ-A) & Rummel $(2005)^{\dagger}$ & calibration of Eq. (33) \\
\hline 3.3 & albedo & $\begin{array}{l}\text { Jaru }(\mathrm{RBJ}-\mathrm{A}) \\
\text { near Manaus }\end{array}$ & Culf et al. $(1995,1996)^{*}$ & $\begin{array}{l}\text { evaluation of recommended para- } \\
\text { meters, re-calibration (Table } 6 \text { ) }\end{array}$ \\
\hline 3.3 & $\begin{array}{l}Q_{L W 0 \downarrow} \\
Q_{P A R 0} \\
Q_{P A R 0}\end{array}$ & $\begin{array}{l}\text { Jaru (RBJA-B) } \\
\text { Jaru (RBJ-A) } \\
\text { Cuieiras (K34) }\end{array}$ & $\begin{array}{l}\text { Andreae et al. (2002) } \\
\text { Rummel (2005) } \\
\text { Araujo et al. }(2002)^{\dagger}\end{array}$ & $\begin{array}{l}\text { evaluation of recommended } \\
\text { parameters (Eqs. 34-36) }\end{array}$ \\
\hline 3.3 & $Q_{P A R}\left(\Lambda_{z}\right)$ & $\begin{array}{l}\text { Jaru (RBJ-A) } \\
\text { Jaru (RBJ-A) } \\
\text { Cuieiras (C14) }\end{array}$ & $\begin{array}{l}\text { McWilliam et al. (1996)*,4 } \\
\text { Rummel (2005) })^{\dagger, 5} \\
\text { Carswell et al. }(2000)^{4}\end{array}$ & $\begin{array}{l}\text { evaluation of recommended and } \\
\text { re-calibrated parameters (see } \\
\text { albedo) }\end{array}$ \\
\hline 3.4 & $v_{c m a 0 h c}$ & $\begin{array}{l}\text { Cuieiras (C14) } \\
\text { Jaru (RBJ-A) }\end{array}$ & $\begin{array}{l}\text { Carswell et al. }(2000)^{6} \\
\text { Lloyd et al. }(1995)^{*, 6}\end{array}$ & calibration of Eq. (32) \\
\hline 3.5 & $\begin{array}{l}F_{\text {csoil }} \\
g_{\text {soil H }}\end{array}$ & Jaru (RBJ-A) & Gut et al. $(2002 a)^{\dagger}$ & $\begin{array}{l}\text { calibration of Eq. (30) } \\
\text { calibration by } \frac{G}{c_{p}^{m} \Delta T}\end{array}$ \\
\hline 3.6 & $\begin{array}{l}A_{n} \\
A_{n}, g_{s}\end{array}$ & $\begin{array}{l}\text { Jaru }(\mathrm{RBJ}-\mathrm{A}) \\
\text { Jaru }\end{array}$ & $\begin{array}{l}\text { McWilliam et al. }(1996)^{*, 6,7} \\
\text { Kuhn et al. }(2002,2004)^{\dagger, 6,8}\end{array}$ & $\begin{array}{l}\text { evaluation of recommended para- } \\
\text { meters and re-calibration }\end{array}$ \\
\hline
\end{tabular}

* Pre-LBA studies 1991-1993; ${ }^{\dagger}$ LBA-EUSTACH, 1999; ${ }^{\star}$ LBA-Claire in July 2001; ${ }^{1}$ derived from literature data after Klinge (1973) and Klinge et al. (1975) for Reserve Ducke in the north of Manaus; ${ }^{2}$ derived by destructive sampling from adjacent clearings for a site $60 \mathrm{~km}$ north of Manaus; ${ }^{3}$ optical method using LAI-2000 Plant Canopy Analyzer; ${ }^{4}$ regular profiles with simultaneous measurements on different heights; ${ }^{5}$ irregular profiles with subsequent measurements on different heights; ${ }^{6}$ combined with leaf area $\left(\Lambda_{z}\right)$ measurements; ${ }^{7}$ porometry measurements on leaves from five tree species in different canopy layers; ${ }^{8} 2-3$ days cuvette measurements on branches from 3 tree species.

1. Simultaneous radiation profile measurements made during ABRACOS from August to September 1992 and from April to June 1993 (six height levels at 35, 21.3, 15.7, 11.6, 6.1, $2.3 \mathrm{~m})$. 2. Measurements made during EUST-II using a single sensor mounted for several days alternately at 51.7, 31.3, 20.5, and $1 \mathrm{~m}$ height (Rummel, 2005). 3. From the study by Carswell et al. (2000), measurements of radiation attenuation, photosynthetic capacity and leaf nitrogen concentration made at the $\mathrm{C} 14$ tower are available for $z=32,28,24$, $16,12,8,4$, and $0 \mathrm{~m}$ height levels within the canopy. Together with leaf nitrogen concentrations measured at RBJ-A (Lloyd et al., 1995) this data is also used to infer the light acclimation (i.e. the distribution of photosynthetic capacity) of the forest canopy. The parameterizations of soil respiration and soil heat flux are inferred using continuous chamber measurements and observed soil temperature and soil surface temperature gradients provided by Gut et al. (2002a). The parameters for the leaf photosynthesis and stomatal mod- els are inferred and evaluated by comparing model predictions with gas exchange measurements sampled on branches and leaves from 8 tree species growing around the tower RBJ-A. The gas exchange data for species $1-3$ is obtained from two to three days of continuous cuvette measurements on tree branches and described and discussed in detail by Kuhn et al. (2002, 2004). We used hourly averages of the raw data, which has been recorded with a time resolution of $5 \mathrm{~min}$. The gas exchange data for species 4-8 were measured with a portable leaf chamber by McWilliam et al. (1996) and represent mean values from three to five single leaves. All data subsets for different species, season, and canopy position have a minimum size of 10 observations and the total number of data points is $N=498$ (183 for species $1-3$ ). 


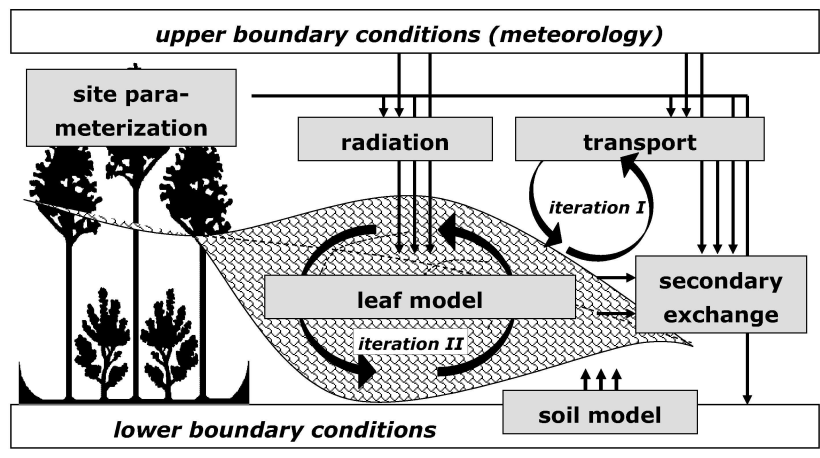

Fig. 2. Sub-models of the modified CANVEG scheme. The two iteration loops $I$ and $I I$ indicate the numerical approach to solve the turbulent exchange and the leaf energy balance, respectively.

\subsection{Model description}

The multilayer model uses two main iteration loops (see Fig. 2) to calculate the coupled exchange of $\mathrm{CO}_{2}$ and energy at the leaf level $(I I)$ and vertical mixing at the canopy level $(I)$, respectively. Spatially, the vertical canopy column is limited by the soil surface and the mean canopy height $h_{c}$. For the application to Amazon rain forest, it is divided into 8 subsequent canopy layers and a single surface layer above the canopy with the upper limit $z_{\text {ref }}$. The scalar conservation equation is applied assuming horizontally homogeneity and steady-state environmental conditions. Vertical transport is calculated using a Lagrangian dispersion scheme (Raupach, 1989), described and evaluated in detail in Simon et al. (2005a). The spatial integration scheme and the numerical algorithm are described in Sect. 2.2.1. The exchange of $\mathrm{CO}_{2}$ and $\mathrm{H}_{2} \mathrm{O}$ is calculated at the leaf level by using a combined stomatal-photosynthesis model for $\mathrm{C}_{3}$ plants (Leuning, 1995). A short description is given in Sect. 2.2.2.

The partitioning, attenuation, and reflectance of radiation within the canopy is very complex and the most sophisticated modeling approaches require detailed information on canopy architecture (leaf angle distribution, clumping factor, etc., see Ross, 1981). Following the scheme of Leuning et al. (1995), we included the approach of Splitters (1986), modified by Goudriaan and van Laar (1994), which accounts for the absorption and reflectance of sunlit and shaded leaves in the visible, near-infrared, long- and short-wave radiation waveband. The non-linear light response of photosynthesis and isoprene emission justify the use of a two-stream radiation model instead of a simple extinction approach. The calculations of canopy radiation are summarized in Sect. 2.2.3.

Driving variables of the CANVEG model are micrometeorological parameters observed at $z_{\text {ref }}$ above the canopy (including $\mathrm{CO}_{2}$ concentration $c_{r e f}$ ) and the temperature, water content and bulk surface conductance of the uppermost soil layer (see Table 3). For the calculation of ozone deposition, the ozone concentration at $z_{\text {ref }}$ is also included
Table 3. Driving variables of the canopy model (subscript ref refers to the reference height above the canopy).

\begin{tabular}{lll}
\hline Parameter & Symbol & Unit \\
\hline local time & $t_{d}, t_{h}$ & {$[$ days, $\mathrm{h}]$} \\
air temperature & $T_{\text {ref }}$ & {$[\mathrm{K}]$} \\
relative humidity & $R H_{\text {ref }}$ & {$[\%]$} \\
barometric pressure & $P_{0}$ & {$[\mathrm{hPa}]$} \\
$\mathrm{CO}_{2}$ concentration & $c_{\text {ref }}$ & {$\left[\mu \mathrm{mol} \mathrm{mol}^{-1}\right]$} \\
incoming global radiation & $g R a d$ & {$\left[\mathrm{~W} \mathrm{~m}^{-2}\right]$} \\
mean horizontal wind speed & $u_{\text {ref }}$ & {$\left[\mathrm{m} \mathrm{s}^{-1}\right]$} \\
standard deviation of vertical & & \\
wind speed & $\sigma_{w r e f}$ & {$\left[\mathrm{~m} \mathrm{~s}^{-1}\right]$} \\
soil temperature & $T_{\text {soil }}$ & {$[\mathrm{K}]$} \\
water filled soil pore space & $\eta_{w}$ & {$[\%]$} \\
bulk soil surface conductance & $g_{\text {soil }}$ & {$\left[\mathrm{mol} \mathrm{m}^{-2} \mathrm{~s}^{-1}\right]$} \\
\hline
\end{tabular}

as input parameter. Since soil surface temperature is given as a lower boundary condition, the soil surface energy balance can be calculated straightforward as described by Garrat (1992). Soil respiration is calculated using an empirical relationship based on soil temperature (see Sect. 2.2.4 for details).

A major problem on linking biochemical leaf models to the canopy scale is the estimation and scaling of leaf physiological parameters (Jarvis, 1993). Extensive studies on nitrogen availability, allocation and optimization (Field, 1983; Field and Mooney, 1986; Walters and Field, 1987; Evans, 1989) led to the development of scaling principles for leaf physiological properties in different ecosystems and across the vertical canopy column (Wullschleger, 1993; Schulze et al., 1994; Leuning et al., 1995). Following these principles, mainly the photosynthetic capacity of sunlit leaves at the canopy top $\left(v_{\text {cmax } 0 h c}\right)$ and the rate of acclimation to light $\left(k_{N}\right)$ have to be specified for a given vegetation type. A semiempirical relationship that couples stomatal conductance to $\mathrm{CO}_{2}$ uptake (Ball et al., 1987) assures that maximum stomatal conductance scales indirectly with maximum photosynthesis. Therefore the stomatal model requires only few site specific informations.

\subsubsection{Spatial integration and numerical algorithm}

For an arbitrary tracer, the net flux at the canopy top $(F)$ is given by the sum of integrated sources and sinks of all $n$ layers $\left(S_{i} \Delta z_{i}\right)$ according to

$F=\sum_{i}^{n} S_{i} \Delta z_{i}$

Each layer has a leaf area $\Delta \Lambda_{i}$ which is used to scale up leaf exchange $\left(F_{\text {leaf }}\right)$ by

$S_{i} \Delta z_{i}=\Delta \Lambda_{i} F_{\text {leaf }}\left(z_{i}\right)$. 
The exchange of sunlit and shaded leaves is treated separately. Therefore, $\Lambda_{i}$ is divided into a sunlit and shaded part, determined by the fraction of sunlit leaves in each layer. For each time step, the ambient air temperature and concentrations of $\mathrm{H}_{2} \mathrm{O}$ and $\mathrm{CO}_{2}$ in each canopy layer are initialized with their values given above the canopy (Table 3). After calculating the absorbed short-wave radiation, the energy balance is solved numerically, separately for sunlit and shaded leaves. After applying Eq. (2), $C_{a}$ is changed by

$\Delta C_{a}\left(z_{j}\right)=\sum_{i}^{n} d(i, j) S_{i} \Delta z_{i}$,

where $d(i, j)$ represents the coefficients of the dispersion matrix connecting the temperature and concentration change $\Delta C_{a}\left(z_{j}\right)$ with $S_{i}$.

The algorithm to solve the coupled equations for $\mathrm{CO}_{2}$ uptake, energy partitioning and vertical mixing can be summarized as follows:

1. Initializing the scalar concentrations $C_{i}=C_{s}=C_{a}=$ $C_{r e f}$.

2. Calculating the source/sink distributions $S_{i}$ (iteration II):

(a) Solving the coupled equations for $\mathrm{CO}_{2}$ and energy exchange at the leaf level, updating $C_{i}, C_{s}$ (Sect. 2.2.2).

(b) Scaling the leaf exchange up to the canopy layer (Eq. 2).

3. Updating $C_{a}$ by $\Delta C_{a}$ (iteration $I$ ), given by the transfer equation (Eq. 3).

Steps $2-3$ are repeated, until the mean temperature change $\sqrt{1 / n \sum \Delta T_{a}^{2}}$ for a new iteration is less than $0.01 \mathrm{~K}$.

\subsubsection{Leaf surface exchange}

A detailed description of the combined stomatalphotosynthesis model is given by Leuning et al. (1995). The numerical approach to solve the coupled equations of leaf surface exchange is described in detail by Wang and Leuning (1998).

In general, net radiation at the leaf surface $\left(Q_{n}\right)$ can be either expressed in terms of a radiation budget or a budget of mass fluxes. The radiation budget gives

$Q_{n}=Q_{S W} \downarrow-Q_{S W} \uparrow+Q_{L W} \downarrow-Q_{L W} \uparrow$

where $\downarrow$ and $\uparrow$ indicating incoming and outgoing directions, respectively. For steady-state conditions, $Q_{n}$ is converted into latent $(L E)$ and sensible heat $(H)$ and chemical energy used for net assimilation $\left(A_{n}\right)$, which gives the budget of mass fluxes

$Q_{n}=\lambda^{m} E+H-\lambda^{C} A_{n}$ where $\lambda^{m}$ and $\lambda^{C}$ represent the molar latent heat of vaporization and the chemical energy for $\mathrm{CO}_{2}$ fixation (according to Jones, 1992, the energy storage into leaf tissue is usually $<5 \%$ on a timescale of one hour). All terms on the right hand side of Eq. (5) can be expressed in a flux-gradient relationship

$$
\begin{aligned}
E & =g_{t w}\left(D_{a}+s \Delta T_{s}\right) \\
H & =g_{t H} c_{p}^{m} \Delta T_{s} \\
A_{n} & =g_{t c} \Delta c_{s},
\end{aligned}
$$

where $g_{t}$ are the total molar conductance for water vapor, heat, and $\mathrm{CO}_{2}$, denoted by subscripts $w, H$, and $c$, respectively. $\left(D_{a}+s \Delta T_{s}\right), \Delta T_{s}$, and $\Delta c_{s}$, are the scalar gradients of water vapor pressure, temperature $\left(T_{s}-T_{a}\right)$, and $\mathrm{CO}_{2}$ $\left(c_{s}-c_{a}\right)$ across the surface pathway from inside the leaf to the ambient air, respectively. $s$ and $c_{p}^{m}$ are the slope relating water vapor pressure to temperature $(d e / d T$ in units of $\mathrm{hPa}$ $\mathrm{K}^{-1}$ ) and the molar specific heat of dry air, respectively. For stomatal controlled transfer $\left(\mathrm{CO}_{2}, \mathrm{H}_{2} \mathrm{O}\right), g_{t}$ can be decomposed to $1 / g_{t}=1 / g_{s}+1 / g_{b}$ (Ball, 1987) where $g_{s}$ and $g_{b}$ are the leaf stomatal and boundary-layer conductance, respectively. For steady state conditions, Eqs. (5-7) can be combined to the Penman-Monteith equation (Monteith, 1965) as

$\lambda^{m} E=\frac{Q_{n}+c_{p}^{m} D_{a} g_{t H}}{1+\frac{\gamma_{a i r}}{s}\left[1+\left(g_{t} H / g_{t w}\right)\right]}$,

where $\gamma_{\text {air }}$ is the psychrometric constant $\left(\mathrm{hPa} \mathrm{K}^{-1}\right)$.

Stomatal conductance for $\mathrm{CO}_{2}\left(g_{s c}\right)$ is linked to $A_{n}$ using the semi-empirical relationship of Ball et al. (1987), hereafter referred to as B87, giving

$g_{s c}=g_{s 0}+a_{A} A_{n} R H_{s} / c_{s}$,

where $g_{s 0}$ is the minimum stomatal conductance, $R H_{S}$ the relative humidity at the leaf surface, and $a_{A}$ an empirical coefficient relating $g_{s}$ to $A_{n}$. The $\mathrm{B} 87$ model has been modified by replacing the dependence on $R H_{s}$ by a function of water pressure deficit $f(D)$ and by including a $\mathrm{CO}_{2}$ compensation point $(\Gamma)$ to avoid $c_{s} \rightarrow 0$ (Leuning, 1990; Lloyd, 1991). Note that some authors also include empirically the role of water availability in the root zone (Wang and Leuning, 1998; Tuzet et al., 2003). Leuning et al. (1995) rewrote the B87 model into

$g_{s c}=g_{s 0}+\frac{a_{A} A_{n}}{\left(c_{s}-\Gamma\right)\left(1+\frac{D_{s}}{D_{s 0}}\right)}$.

by applying the Lohammer function $f(D)=1+D_{s} / D_{s 0}$ for humidity response (Lohammer et al., 1980), where $D_{s}$ and $D_{s 0}$ represent the water vapor pressure deficit at the leaf surface and an empirical coefficient, respectively. $g_{s}$ for water and other scalars can be obtained by multiplying $g_{s c}$ with the ratio of molecular diffusivities (Ball, 1987).

The biochemical leaf model of leaf photosynthesis for $\mathrm{C}_{3}$ plants was originally developed by Farquhar et al. (1980) and 
Caemmerer and Farquhar (1981). We implemented the combined approach of Leuning et al. (1995), who identify three different processes constraining $A_{n}$ : (1) the biochemical demand for $\mathrm{CO}_{2}$ inside the chloroplast, (2) the supply of $\mathrm{CO}_{2}$ by diffusion through the stomata and the leaf boundary layer ( $c_{i}=c_{a}+A_{n} / g_{t}$, Eq. 8) and (3) the stomatal response to $A_{n}$ (Eq. 11) which constrains again the demand function. A general description for the demand of $\mathrm{CO}_{2}$ is given by

$$
A_{n}=\min \left\{A_{v}, A_{J}\right\}-R_{d}
$$

where $A_{v}$ is the gross rate of photosynthesis limited by the biochemical fixation of $\mathrm{CO}_{2}$ and $A_{J}$ the rate of photosynthesis limited by the regeneration of $\mathrm{CO}_{2}$ acceptors. In the case of $\mathrm{C}_{3}$ plants, $A_{v}$ is limited by the $\mathrm{CO}_{2}$ dependent activity of Ribulose bisphosphate carboxylase-oxygenase (Rubisco) $v_{c m a x}$, which depends on $\mathrm{CO}_{2}$ and oxygen concentration $\left(o_{i}\right)$ inside the leaf and the Michaelis coefficients for carboxylation $\left(K_{c}\right)$ and oxygenation $\left(K_{o}\right)$ according to

$$
A_{v}=v_{\text {cmax }} \frac{c_{i}-\Gamma_{*}}{c_{i}+K_{c}\left(1+o_{i} / K_{o}\right)} \text {. }
$$

For $\mathrm{C}_{4}$ plants, a similar approach has been developed by Collatz et al. (1992). $A_{J}$ is limited by the regeneration of Ribulose bisphosphate $\left(\mathrm{RuP}_{2}\right)$, which depends on the light driven rate of electron transport across the chloroplast membrane $(J)$. The actual rate $J$ is the smaller root of a hyperbolic function, determined by the maximum rate for electron transport $\left(J_{\max }\right)$, leaf absorbed radiation $\left(Q_{a b s}\right)$, light use efficiency $(\alpha)$ and a parameter determining the shape of the transition of the rectangular light response curve from linear increase to saturation $(\theta)$ :

$\theta J^{2}-\left(\alpha Q_{a b s}+J_{\max }\right) J+\alpha Q_{a b s} J_{\max }=0$.

All parameter values required to solve the coupled leaf model are listed in Table 4 . Leaf respiration $\left(R_{d}\right)$ and the maximum rate of electron transport $\left(J_{\max }\right)$ at a reference leaf temperature $T_{s 0}$ are calculated as a fixed proportion of $v_{\text {cmax } 0}$. Temperature kinetics of $R_{d}, K_{c}$ and $K_{o}$ are calculated according to Harley et al. (1992) and Leuning et al. (1995), requiring appropriate values for activation $\left(H_{a}\right)$ and deactivation $\left(H_{d}\right)$ and, for $v_{c \max }$ and $J_{\max }$ also for entropy $\left(S_{v}, S_{j}\right)$. The coefficients $\gamma_{0-2}$, listed in Table 4 , are required to calculate the temperature dependence of the $\mathrm{CO}_{2}$ compensation point in the absence of day respiration.

According to Monteith (1973), the conductance at the leaf boundary-layer $\left(g_{b}\right)$ can be decomposed into a forced $\left(g_{b u}\right)$ and free convective $\left(g_{b f}\right)$ part

$g_{b}=g_{b u}+g_{b f}$.

The single-sided forced and free convective leaf boundary layer conductance for heat ( $g_{b u H}$ and $g_{b H f}$, respectively) are given by

$$
\begin{aligned}
& g_{b H u}=0.003 \sqrt{u / w_{l}} \\
& g_{b H f}=0.5 D_{H} G r^{1 / 4} / w_{l}
\end{aligned}
$$

Table 4. Photosynthesis and stomatal conductance model parameters. Marked values are taken from ${ }^{\dagger}$ Ball et al. (1987), ${ }^{\ddagger}$ Farquhar et al. (1980), ${ }^{*}$ Leuning et al. (1995) and ${ }^{\dagger}$ Harley et al. (1992). Values in brackets represent parameter modifications, suggested by leaf level gas exchange measurements (Sect. 3.6). The reference leaf temperature $T_{S 0}$ is set to $298.15 \mathrm{~K}$ for tropical plants (Lloyd et al., 1995). $v_{\text {cmax } 0 h c}$ and the light acclimation parameter $k_{N}$ are derived from observations (in Sect. 3.4).

\begin{tabular}{lll}
\hline Parameter & Value (optimized) & Unit \\
\hline$a_{A}$ & $10^{\dagger}$ & {$[-]$} \\
$g_{s 0}$ & $0.01^{\dagger}$ & {$\left[\mathrm{mol} \mathrm{m}^{-2} \mathrm{~s}^{-1}\right]$} \\
$D_{s 0}$ & $15^{*}$ & {$[\mathrm{hPa}]$} \\
$v_{c m a x} 0 h c$ & 50 & {$\left[\mu \mathrm{mol} \mathrm{m}^{-2} \mathrm{~s}^{-1}\right]$} \\
$k_{N}$ & 0.2 & {$[-]$} \\
$T_{s 0}$ & 298.15 & {$[\mathrm{~K}]$} \\
$J_{\text {max } 0}$ & $2.1 v_{\text {cmax }} 0^{*}$ & {$\left[\mu \mathrm{mol} \mathrm{m}^{-2} \mathrm{~s}^{-1}\right]$} \\
$R_{d 0}$ & $0.01 v_{\text {cmax } 0} *$ & {$\left[\mu \mathrm{mol} \mathrm{m}^{-2} \mathrm{~s}^{-1}\right]$} \\
$o_{i}$ & $210^{\ddagger}$ & {$\left[\mathrm{mmol} \mathrm{mol}^{-1}\right]$} \\
\hline$\alpha$ & $0.2^{*}(0.15)$ & {$\left[\mathrm{mol} \mathrm{e} \mathrm{mol}^{-1} \mathrm{quanta}^{*}\right]$} \\
$\theta$ & $0.9^{*}$ & {$[-]$} \\
$K_{c 0}$ & $302^{*}$ & {$\left[\mu \mathrm{mol}^{-1}\right]$} \\
$K_{o 0}$ & $256^{*}$ & {$\left[\mathrm{mmol}^{-1}\right]$} \\
$H_{K c}$ & $59.4^{\dagger}$ & {$\left[\mathrm{kJ} \mathrm{mol}^{-1}\right]$} \\
$H_{K o}$ & $36^{\dagger}$ & {$\left[\mathrm{kJ} \mathrm{mol}^{-1}\right]$} \\
$H_{R d}$ & $53^{\dagger}$ & {$\left[\mathrm{kJ} \mathrm{mol}^{-1}\right]$} \\
$H_{v V}$ & $116.3^{\dagger}$ & {$\left[\mathrm{kJ} \mathrm{mol}{ }^{-1}\right]$} \\
$H_{d V}$ & $202.9^{\dagger}$ & {$\left[\mathrm{kJ} \mathrm{mol}^{-1}\right]$} \\
$H_{v J}$ & $79.5^{\dagger}(108)$ & {$\left[\mathrm{kJ} \mathrm{mol}^{-1}\right]$} \\
$H_{d J}$ & $201^{\dagger}$ & {$\left[\mathrm{kJ} \mathrm{mol}^{-1}\right]$} \\
$S_{v}$ & $0.65^{\dagger}$ & {$\left[\mathrm{kJ} \mathrm{mol}^{-1}\right]$} \\
$S_{j}$ & $0.65^{\dagger}(0.66)$ & {$\left[\mathrm{kJ} \mathrm{mol}^{-1}\right]$} \\
$\gamma_{0}$ & $34.6^{*}$ & {$\left[\mu \mathrm{mol} \mathrm{mol}^{-1}\right]$} \\
$\gamma_{1}$ & $0.0451^{*}$ & {$[-]$} \\
$\gamma_{2}$ & $0.000347^{*}$ & {$[-]$} \\
\hline & &
\end{tabular}

where $u, w_{l}, D_{H}$ and $G r$ are the mean horizontal wind speed, mean leaf width, the molecular diffusivity for heat and the Grashof number, respectively. $G r$ is calculated from $\Delta T_{s}$ according to $G r=1.6 \times 10^{8}\left|\Delta T_{s}\right| w_{l}^{3} . w_{l}$ is estimated as $0.15 \mathrm{~m}$ from a large collection of leaves from Amazonian tree species (Ribeiro et al., 1999).

\subsubsection{Radiation}

Absorbed radiation of shaded leaves $\left(Q_{S H}\right)$ is defined by the sum of diffusive and scattered beam radiation. The absorbed radiation of sunlit leaves $\left(Q_{S L}\right)$ includes additionally a direct beam component leading to

$$
\begin{aligned}
Q_{S H}\left(\Lambda_{z}\right) & =Q_{d}\left(\Lambda_{z}\right)+Q_{s b}\left(\Lambda_{z}\right) \\
Q_{S L}\left(\Lambda_{z}\right) & =Q_{b}\left(\Lambda_{z}\right)+Q_{S H}\left(\Lambda_{z}\right),
\end{aligned}
$$


where $\Lambda_{z}$ is the cumulative leaf area above $z$. Diffusive, scattered, and direct beam components denoted by subscripts $d, s b$ and $b$, respectively, are calculated according to

$$
\begin{aligned}
Q_{d}\left(\Lambda_{z}\right) & =Q_{d 0} k_{d}\left(1-\rho_{c d}\right) \exp \left(-k_{d} \Lambda_{z}\right) \\
Q_{s b}\left(\Lambda_{z}\right) & =Q_{b 0} k_{b}\left(1-\rho_{c b}\right) \exp \left(-k_{b} \Lambda_{z}\right)-Q_{b}\left(\Lambda_{z}\right) \\
Q_{b}\left(\Lambda_{z}\right) & =Q_{b 0} k_{b}^{B}\left(1-\sigma_{l}\right) \exp \left(-k_{b}^{B} \Lambda_{z}\right)
\end{aligned}
$$

where $\sigma_{l}, \rho_{c}$, and $k$ are the scattering (reflection plus transmission), canopy reflection, and extinction coefficients, respectively $k^{B}$ is the extinction coefficient for black leaves (with no reflection or transmission). The scattered direct beam radiation is obtained by subtracting $Q_{b}$ from the total absorbed beam radiation (direct + scattered). The fraction of sunlit leaves $\left(f_{S L}\right)$ is calculated as $f_{S L}\left(\Lambda_{z}\right)=\exp \left(-k_{b} \Lambda_{z}\right)$ by

The net long-wave radiation of a body is generally given

$Q_{L W}=Q_{L W} \downarrow-Q_{L W} \uparrow=\epsilon_{a} \sigma_{B} T_{a}^{4}-\epsilon_{s} \sigma_{B} T_{s}^{4}$,

where $\epsilon_{s}, \epsilon_{a}$ and $T_{s}, T_{a}$ represent the emissivity and temperature of the body and ambient air and $\downarrow$ and $\uparrow$ denote the incoming and outgoing parts of $Q_{L W}$, respectively. $\sigma_{B}$ is the Stefan-Boltzmann constant. $\epsilon_{s}$ has different values for soil and leaf surfaces given as $\epsilon_{l}=0.96$ and $\epsilon_{\text {soil }}=0.94$, respectively, (Wang and Leuning, 1998). Incoming long-wave radiation $\left(Q_{L W \downarrow}\right)$ is calculated analogously to diffusive radiation according to

$Q_{L W \downarrow}\left(\Lambda_{z}\right)=\epsilon_{a 0} \sigma_{B} T_{r e f}^{4} k_{d}^{B} \exp \left(-k_{d}^{B} \Lambda_{z}\right)$.

The outgoing long wave radiation given as $Q_{L W \uparrow}\left(\Lambda_{z}\right)=\epsilon_{S} \sigma_{B} T_{S}\left(\Lambda_{z}\right)^{4}$ can not be solved directly, since $T_{S}$ is part of the leaf energy balance. Instead, the isothermal outgoing long wave radiation $\left(Q_{L W \uparrow}^{*}\right)$, equivalent to the long wave radiation that would be lost, if the surface were at ambient temperature (Jones, 1992) is calculated by replacing $T_{r e f}$ and $\epsilon_{a 0}$ in Eq. (24) with $T_{a}\left(\Lambda_{z}\right)$ and $\epsilon_{s}$, respectively. The isothermal net radiation $\left(Q_{n} *\right)$ is then given by

$Q_{n}^{*}=Q_{S W \downarrow}-Q_{S W \uparrow}+Q_{L W \downarrow}-Q_{L W \uparrow}^{*}$

Combining Eqs. (25) and (4) leads to

$Q_{n}^{*}=Q_{n}+\sigma_{B} \epsilon_{s}\left(T_{s}^{4}-T_{a}^{4}\right)$.

Substituting $T_{s}=T_{a}+\Delta T_{s}$ and expanding Eq. (26) cancels $T_{a}^{4}$ out. Second or higher power terms including $\Delta T_{s}$ can be neglected since $\Delta T_{s} \ll T_{a}$ which leaves

$Q_{n} \simeq Q_{n}^{*}-\sigma_{B} \epsilon_{\Lambda} 4 T_{a}^{3} \Delta T_{s}$

where $g_{r a d}=\epsilon \sigma_{B} 4 T_{a}^{3} / c_{p}^{m}$ is defined as the radiative conductance.

\subsubsection{Parameterization of soil surface exchange}

Soil evaporation is calculated by solving the PenmanMonteith equation for a bulk soil surface layer from -0.05 to $1 \mathrm{~m}$ height. The solution, described in more detail in Garrat (1992), requires the soil relative humidity $\left(R H_{\text {soil }}\right)$ and the bulk soil surface conductance $\left(g_{\text {soil }}\right)$ as input parameters. $R H_{\text {soil }}$ is related to the soil matrix potential $\left(\psi_{\text {soil }}\right)$ according to

$R H_{\text {soil }}=\exp \left(\frac{-g \psi_{\text {soil }}}{R T_{\text {soil }}}\right)$

whereas $g$ and $R$ are the gravity and the universal gas constant, respectively. $\psi_{\text {soil }}$ is calculated from the volumetric soil water content $\left(\eta_{w}\right)$ according to

$\psi_{\text {soil }}=\psi_{\text {soil }}^{*}\left(\eta_{w} / \eta_{w}^{*}\right)^{-a_{\psi}}$

with $\eta_{w}^{*}, \psi_{\text {soil }}^{*}$, and $a_{\psi}$ being the total soil pore space, $\psi_{\text {soil }}$ at saturation, and an empirical coefficient, respectively. For a sandy loam, which is the dominant soil type at the Jaru site, Garrat (1992) proposes a maximum matrix potential of $\psi_{\text {soil }}^{*}=-0.218$, a coefficient value of $a_{\psi}=4.9$, and a maximum water filled pore space of $\eta_{w}^{*} \approx 0.5$ which is in agreement with the value given by Gut et al. (2002b) for the Jaru site.

For soil respiration $\left(F_{c s o i l}\right)$, the simple Arrhenius curve

$F_{\text {csoil }}=F_{\text {csoil } 0} \exp \left[H_{\text {asoil }} / R T_{\text {soil } 0}\left(1-T_{\text {soil } 0} / T_{\text {soil }}\right)\right]$

is applied, where $F_{c s o i l 0}$ is the soil respiration at a reference temperature $T_{\text {soil }}$ and $H_{\text {asoil }}$ the activation energy (Tuzet et al., 2003).

\subsection{Model parameterization}

The characterization of canopy structure represents a model key parameter. Firstly, the source/sink strength is a linear function of the leaf area of each canopy layer (Eq. 2). Secondly, it determines light extinction within the canopy and, indirectly, the scaling of leaf biochemistry (see above). Commonly, canopy structure is defined in terms of accumulated leaf area $\Lambda_{z}$. Denoting the mean canopy height as $h_{c}$ gives $\Lambda_{h c}=0$ and $\Lambda_{0}=$ total LAI (leaf area index in units of $\mathrm{m}^{2}$ leaf $\mathrm{m}^{-2}$ ground). In the present study, a bi-modal vertical leaf area distribution with a lower and upper canopy maximum is assumed. This characterization is implemented as the weighted sum of two beta functions given as

$\Lambda_{z}=\Lambda_{0} \sum_{i=B, T} I_{x(z, i)}\left(a_{i 1}, a_{i 2}\right) w_{i}$,

where $I_{x(z, i)}$ is the beta distribution function, which has limiting values $I_{0}=0$ and $I_{1}=1$ (Press, 1997). $x(z)$ represents the linearly transformed height $x=1-z / z_{i} *$ with the upper boundary $z_{i}^{*}$ (e.g. $z_{2}^{*}=h_{c}$ for the distribution from the ground to the canopy top). Each mode function has two shape parameters $a_{i 1}$ and $a_{i 2}$ and is weighted by the fractions of each 

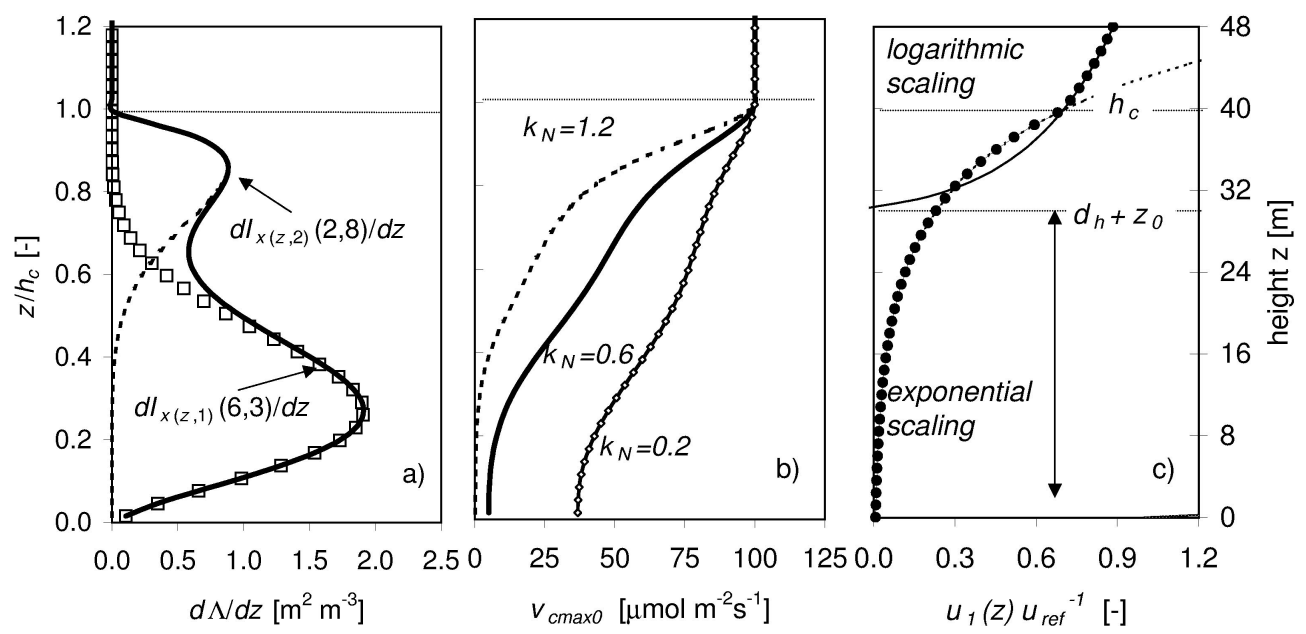

Fig. 3. Site specific profile parameterizations (examples). (a) The leaf area density profile $(d \Lambda(z) / d z)$, implemented as the sum of two beta distributions (solid line) with an upper (dashed line) and lower (open squares) canopy maximum (LAI=1, lower maximum weight $w_{1}=0.75$. (b) Corresponding light acclimation of leaf biochemistry using different values of extinction $\left(k_{N}\right)$. (c) Logarithmic (above canopy, solid line), exponential (below $h_{c}$, dashed line) and combined (closed circles) scaling of horizontal wind speed $\left(u_{1}(z)\right)$. $h_{c}, z_{0}$ and $d_{h}$ are the canopy height, roughness length and zero length displacement height, respectively. At $z_{0}+d_{h}$, the logarithmic profiles crosses zero.

distribution on total LAI $\left(w_{i}\right)$. An example for Eq. (31) is given in Fig. 3a. Further ecological applications of the useful beta function are given in (Meyers and Paw U, 1986; McNaughton, 1994; Simon et al., 2005a).

In the next step, $\Lambda_{z}$ is used for a vertical scaling of leaf physiological parameters. According to the light acclimation hypothesis, photosynthetic capacity of single leaves, expressed as the maximum rate of carboxylation at a reference temperature $\left(v_{\operatorname{cmax} 0}\right)$, is co-distributed optimally with leaf nitrogen concentration $\left(c_{N}\right)$, following the mean light gradients inside the canopy to maximize carbon gain (Field, 1983; Hirose et al., 1988; Leuning, 1995; Hirose and Bazzaz, 1998; Niinemets et al., 1999). Up to now, only a few observations of the degree of light acclimation in natural canopies exist (e.g. in Meir et al., 2002). Assuming a linear relationship between $v_{\text {cmax } 0}$ and $c_{N}$, Leuning et al. (1995) proposed

$v_{c \max 0}\left(\Lambda_{z}\right)=v_{c \max 0 h c} \exp \left(-k_{N} \Lambda_{z}\right)$,

where $k_{N}$ is an extinction coefficient specifying the degree of acclimation and $v_{\text {cmax } 0 h c}$ the value of $v_{\text {cmax } 0}$ at the canopy top. For illustration, Eq. (32) is applied using different values for $k_{N}$ for a given canopy structure (Fig. 3b). A high value of $k_{N}$ is associated with a strong decrease of $v_{c m a x 0}$. Based on nitrogen availability, $v_{\text {cmax } 0 h c}$ can be inferred from ecological principles: for tropical rain forest a low nitrogen availability, and consequently a relatively small value of $v_{\text {cmax } 0 h c} \approx 50 \mu \mathrm{mol} \mathrm{m} \mathrm{m}^{-2} \mathrm{~s}^{-1}$ can be assumed (Schulze et al., 1994). The remaining parameters of the leaf models are set to the values listed in Table 4. In Sect. 3.4, the value of $v_{\text {cmax } 0 h c}=50 \mu \mathrm{mol} \mathrm{m} \mathrm{m}^{-2} \mathrm{~s}^{-1}$ is tested and $k_{N}$ is inferred.

The calculation of the leaf boundary-layer resistance (see Sect. 2.2.2) requires a parameterization of the profile of hor- izontal wind speed $u(z)$. We use a slightly modified version of the combined approach of Kaimal and Finnigan (1994), applying a logarithmic decrease above and an exponential decrease below the canopy height $\left(h_{c}\right)$ according to

$u(z)=\left\{\begin{array}{rl}u_{r e f} a_{u} \ln \left(\frac{z-d_{h}}{z_{0}}\right) & ; z \geq h_{c} \\ u_{0}+u\left(h_{c}\right) \exp \left[-k_{u} \Lambda_{0}\left(1-z / h_{c}\right)\right] & ; \text { else }\end{array}\right.$,

where $a_{u}$ and $k_{u}$ are two empirical coefficients, and $z_{0}$, and $d_{h}$ the roughness length and the displacement height below $h_{c}$, respectively (see Fig. $3 \mathrm{c}$ for an example). $u_{0}(z)$ represents a minimum value of $u(z)$ that does not scale with $u_{r e f}$. $z_{0}$ and $d_{h}$ are set to $1.3 \mathrm{~m}$ and $29 \mathrm{~m}$, respectively (see also Rummel, 2005). The remaining parameter values are derived by fitting Eq. (33) to profile measurements made above $\left(a_{u}\right)$ and within the canopy $\left(k_{u}\right)$.

Atmospheric emissivity $\left(\epsilon_{a 0}\right)$ is required to calculate the incoming long-wave radiation and derived using the empirical relationship of Brutsaert (1975) giving

$\epsilon_{a 0}=1.24\left(\frac{e_{\text {ref }}}{T_{\text {ref }}}\right)^{1 / 7}$,

where $e_{\text {ref }}$ and $T_{\text {ref }}$ are the water vapor pressure $(\mathrm{hPa})$ and temperature $(\mathrm{K})$ above the canopy.

According to Jones (1992), the incoming visible radiation $\left(Q_{V 0}\right)$ can be calculated from the incoming global radiation $(\mathrm{g} R \mathrm{Rd})$ as

$Q_{V 0}=0.45 \mathrm{~g} \operatorname{Rad}$

(note that $Q_{V 0}$ and $g R a d$ are in units of $\mathrm{W} \mathrm{m}^{-2}$ ). At the leaf level, the absorbed visible radiation $\left(Q_{V}\right)$ is used to calculate 
Table 5. Derived parameter values for Eq. (31) (LAI $\Lambda_{0}=6$, symbols $w_{i}, a_{i 1}, a_{i 2}, z_{i}^{*}$ represent dimensionless weights, the two parameters of the incomplete beta function and the scaling heights in units of meters above ground, respectively). Numbers in brackets represent values estimated for dense $\left(\Lambda_{0}=6.5\right.$ denoted as +$)$ and open palm rich $\left(\Lambda_{0}=5.5\right.$ denoted as -$)$ forest types.

\begin{tabular}{llllll}
\hline$i$ & canopy layer & $w_{i}(+,-)$ & $z_{i}^{*}(+,-)$ & $a_{i 1}$ & $a_{i 2}$ \\
\hline$T$ & top & $0.75(0.85,0.65)$ & $40(42,34)$ & 4.2 & 4.6 \\
$B$ & bottom & $0.25(0.15,0.35)$ & $13(8,13)$ & 2.3 & 1.1 \\
\hline
\end{tabular}

the photosynthetic active radiation $\left(Q_{P A R}\right.$ in units of $\mu \mathrm{mol}$ $\mathrm{m}^{-2} \mathrm{~s}^{-1}$ ) according to

$Q_{P A R}=4.5 \mu \mathrm{mol} \mathrm{J}^{-1} Q_{V}$.

The soil heat flux is calculated by solving the PenmanMonteith equation for the pathway from the soil surface to the ambient air layer above. The bulk soil surface conductance for heat $\left(g_{\text {soil } H}\right)$ is derived by linear fitting of the fluxgradient-relationship $G=g_{s o i l H} c_{p}^{m} \Delta T$, where $G, c_{p}^{m}$, and $\Delta T\left(z_{1}, z_{2}\right)$ represent the soil heat flux (observed), the specific heat capacity of air (constant) and the temperature gradient between $z_{1}=-0.05 \mathrm{~m}$ and $z_{2}=1 \mathrm{~m}$ (observed), respectively. Soil evaporation and respiration are calculated as described in Sect. 2.2.4. The Arrhenius curve to predict soil respiration is derived from observations from soil chamber measurements. The parameterization of soil evaporation (see Sect. 2.2.4) is not evaluated independently here, since appropriate data sets are missing. Jones (1992) estimates that $E_{\text {soil }}$ is usually less than $5 \%$ of the total evapotranspiration for canopies with a total LAI of 4 and more, even when the soil surface is wet.

\section{Results and discussion}

In the following sections, the data sets listed in Table 2 are used to characterize the rain forest canopy (canopy structure, extinction profile of horizontal wind speed, canopy albedo, canopy biochemistry) and to derive or evaluate important model parameter values (number of model layers, bulk soil surface conductance). The leaf models for photosynthesis and stomatal conductance are evaluated with scale appropriate data (leaf chamber and cuvette measurements) and the sensitivity of predicted canopy net fluxes of $\mathrm{CO}_{2}$ and energy is assessed with respect to the uncertainties of key parameters derived before.

\subsection{Characterization of canopy structure}

All available measurements of canopy structure listed in Table 2 are fitted to Eq. (31). For this, all observations listed
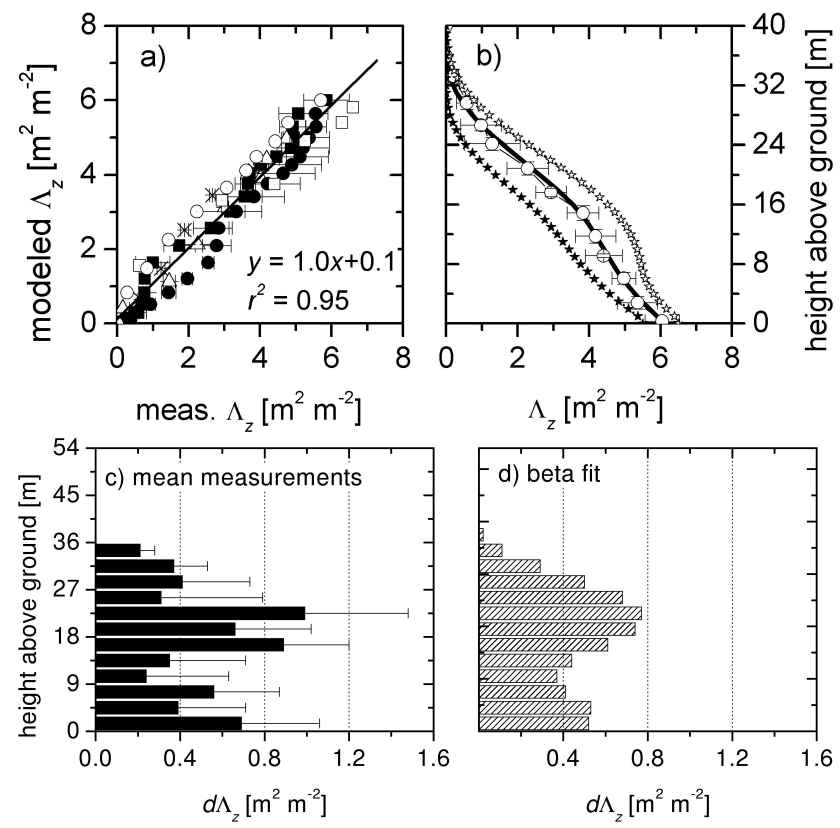

Fig. 4. Parameterization of canopy structure and accumulated leaf area $\Lambda_{z}$. (a) Model comparison with field data of Roberts et al. (1993) (open squares) and McWilliam et al. (1993) (open circles), and measurements made at the towers K34 (open triangles), C14 (stars) RBJ-A (closed squares) and RBJ-B (closed circles, see Table 2). (b) Observed accumulated leaf area $\left(\Lambda_{z}\right)$ for averaged $3 \mathrm{~m}$ height intervals (open circles with standard deviations) and predicted for a mean (solid line), dense (open stars) and open (closed stars) forest type. (c) Mean observed and (d) predicted differential leaf area for $3 \mathrm{~m}$ height intervals.

in Table 2 are averaged for $3 \mathrm{~m}$ height intervals, representing the mean of observations. The upper canopy height is estimated as $h_{c}=40 \mathrm{~m}$ (Klinge et al., 1975; McWilliam et al., 1993; Roberts et al., 1993; Kruijt et al., 2000; Andreae et al., 2002; Rummel et al., 2002; Simon et al., 2005a). Total LAI is calculated as $\Lambda_{0}=6$, representing the mean value of all measurements. The remaining parameters of Eq. (31) have to be found by non-linear optimization: Considering literature data and ecological principles, we assume a lower and upper leaf area density maximum at $0-5$ and $15-30 \mathrm{~m}$ height, reflecting the ground vegetation and small trees in the lower canopy and tall trees, lianes, and epiphyta in the upper canopy, respectively. A priori, we estimated the weights and upper bounds of the two superimposing distributions as $w_{B}=0.25, w_{T}=0.75$ and $z_{B}^{*}=13 \mathrm{~m}, z_{T}^{*}=h_{c}(40 \mathrm{~m})$. Application of a least-squares method leads to locally optimized parameter values of $a_{i 1}$ and $a_{i 2}$. All parameter values are listed in Table 5, including also estimates for a "dense forest type" with higher leaf area densities in the upper canopy (LAI=6.5) and for an "open forest type" with higher densities near the ground (LAI=5.5). The scatter plot (Fig. 4a) and the mean vertical profiles (Fig. 4b) show a good agreement between 


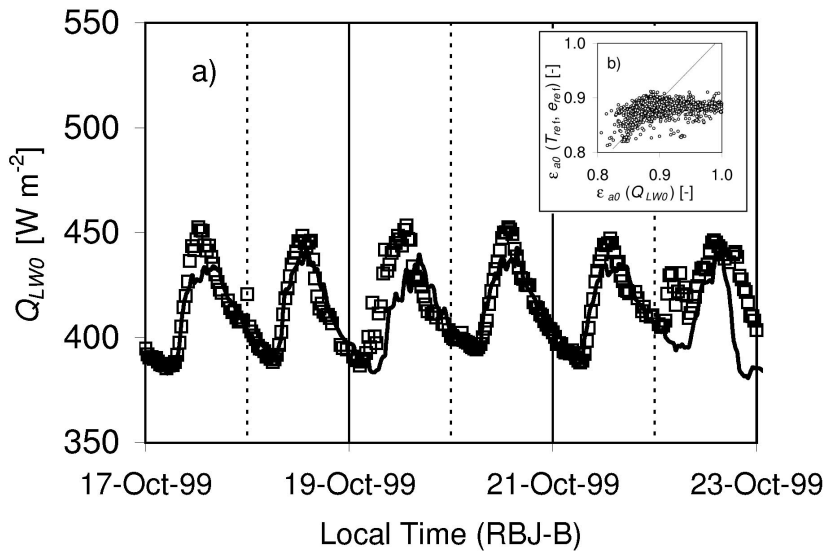

Fig. 5. Observed and predicted Atmospheric emissivity $\left(\epsilon_{a 0}\right)$ and incoming long-wave radiation $\left(Q_{L W \downarrow}\right)$ at the tower RBJ-B for a one week period. (a) Measured (open squares) and predicted time series (solid line) for $Q_{L W \downarrow}$. (b) $\epsilon_{a 0}\left(T_{r e f}, e_{r e f}\right)$ plotted against $\epsilon_{a 0}\left(Q_{L W 0}\right)$ (parameterized versus observed atmospheric emissivity, respectively).

measurements and predictions $\left(r^{2}=0.95\right)$. The modifications for dense and open forest types are derived from the standard deviations of mean values. The mean differential profile $\left(d \Lambda_{z}\right.$ for $3 \mathrm{~m}$ height intervals, see Fig. $\left.4 \mathrm{c}\right)$ is scattered but shows clearly two different modes.

The characterization described above may be helpful for future modeling studies where a definition of canopy structure is required. Variations of the vegetation type may be considered by modifying the parameters values listed in Table 5 .

\subsection{Horizontal wind speed}

The parameters of the function describing the profile of horizontal wind speed $(u(z))$ have been derived using observations at the Jaru site (Table 2). The measurements suggest a significant positive intercept $u_{0}$, which decreases with height according to $u_{0}(z)=0.1 \mathrm{~m} \mathrm{~s}^{-1}, z \leq d_{h}$ and $u_{0}(z)=0.1\left[1-\left(z-d_{h}\right) /\left(z_{\text {ref }}-d_{h}\right)\right], z>d_{h}$. The logarithmic part of Eq. (33) is derived by a non-linear fit, resulting in $z_{0}=1.3 \mathrm{~m}, d_{h}=29 \mathrm{~m}$ and $a_{u 1}=1 / 3$. Linear-fitting of the exponential part of Eq. (33) predicts an extinction coefficient $k_{u}=0.8$. The linear correlation between all measurements and the parameterization is $r^{2}=0.94(y=0.00+1.02 x)$ showing no systematic deviations.

\subsection{Radiation}

The empirical relationship between atmospheric emissivity $\left(\epsilon_{a 0}\right)$ and water vapor pressure and temperature ( $T_{r e f}$, Eq. 34) is evaluated by a comparison of simulated and observed $\epsilon_{a 0}$ and incoming long-wave radiation $\left(Q_{L W \downarrow}\right)$ measured at the RBJ-B tower (Fig. 5). For high emissivity values $\left(\epsilon_{a 0}>0.9\right)$,
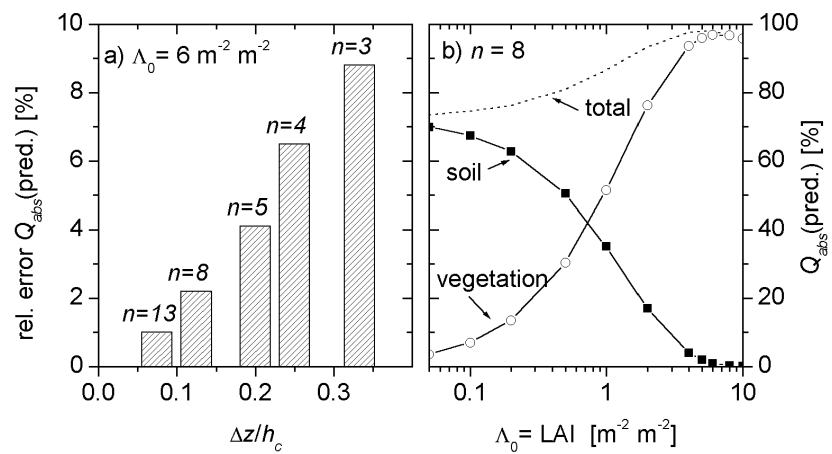

Fig. 6. Absorbed radiation $\left(Q_{a b s}\right)$ and albedo in relation to the number of canopy layers, leaf area index, and leaf optical parameters for a canopy with black leaves (no reflectance and transmittance) at midday and clear sky conditions with a diffusive fraction $f_{d 0}=0.2$. (a) Relative error of predicted absorbed radiation in relation to the number $(n)$ and thickness $\left(\Delta z / h_{c}\right)$ of canopy layers (total leaf area index $\Lambda_{0}=6$ ). (b) Predicted total (dotted line), soil (line with filled squares), and vegetation (line with open circles) fractions of absorbed radiation plotted against LAI $(n=8, \Delta z=4$ $\mathrm{m}=0.125 \mathrm{z} / \mathrm{hc})$.

the parameterization shows a systematic error of $1-10 \%$, resulting in an underestimation of $10-20 \mathrm{~W} \mathrm{~m}^{-2}$ for $Q_{L W \downarrow}$ at noon time. However, this is less than $5 \%$ on relative terms since $Q_{L W \downarrow}$ is mainly determined by $T_{r e f}$.

The number $(n)$ and thickness $\left(\Delta_{z}\right)$ of canopy layers are parameters that determine model accuracy and numerical stability. To infer the sensitivity of predicted absorbed radiation in relation to the number of model layers, we assumed a canopy with black leaves (no albedo !). As shown in Fig. 6a, the relative error of predicted absorbed radiation $\left(Q_{a b s}\right)$ increases linearly from $1 \%$ for $n=13(\Delta z=3 \mathrm{~m})$ to $9 \%$ for $n=3$ $(\Delta z=13.3 \mathrm{~m})$. Note that since all incoming radiation of a canopy with black leaves is absorbed, the relative error is defined as $\left(Q_{a b s}^{\text {model }}-Q_{0}\right) / Q_{0}$. As a good compromise between prediction error and computational costs, a number of $n=8$ canopy layers is derived. In fact this meets the accuracy criteria of Norman and Welles (1983) closely, recommending a maximum leaf area of 0.5 for a given model layer. For an open canopy, predicted absorbed radiation is also dependent on LAI (Fig. 6b). However, for $\mathrm{LAI} \geq 4$, the soil absorbs only little energy while more than $90 \%$ of incoming short-wave radiation is absorbed by leaves. This implies a low sensitivity of predicted canopy net fluxes in relation to the uncertainty of LAI. This point is discussed in more detail in Sect. 3.7.

Green leaves partially reflect and transmit the incident radiation, which is considered by two model parameters, the leaf scattering $\left(\sigma_{l}\right)$ and the canopy reflection $\left(\rho_{c}\right)$ coefficients, respectively. In Fig. 7, the predicted canopy albedo for clear sky conditions at midday is compared to longterm observations made by Culf et al. (1995) and Culf et al. (1996) at the Jaru site and at a second site near Manaus. Using 


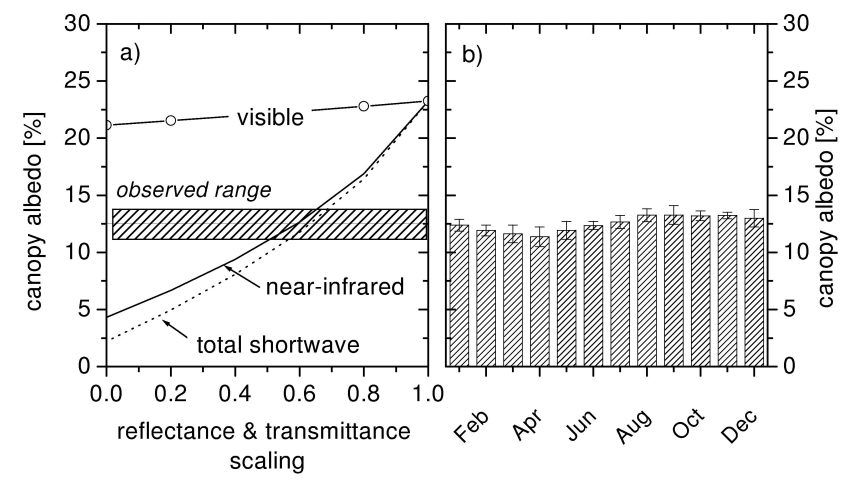

Fig. 7. (a) Observed (hatched box) and predicted canopy albedo at noon time for clear sky conditions $\left(f_{d 0}=0.2\right)$ as a function of relative canopy reflectance and transmittance $(1.0=$ recommended parameter values, $0.0=$ black leaves) for visible (line with open circles), near-infrared (solid line) and total short-wave radiation (dotted line). (b) Annual cycle of canopy albedo as observed at the Jaru site and a second site near Manaus (Reserva Duke) in 1991-1993 (Culf et al., 1995, 1996). Mean and standard deviations of monthly values for both sites are shown $\left(r^{2}=0.87\right)$.

Table 6. Leaf optical parameters as recommended by Leuning et al. (1995) and derived by fitting predicted canopy albedo to observations (see Fig. 7).

\begin{tabular}{lllll}
\hline $\begin{array}{l}\text { Parameter } \\
\text { scaling }\end{array}$ & $\begin{array}{l}\text { recommended } \\
1.00\end{array}$ & $\begin{array}{l}\text { mean } \\
0.66\end{array}$ & $\begin{array}{l}\text { wet season } \\
0.60\end{array}$ & $\begin{array}{l}\text { dry season } \\
0.75\end{array}$ \\
\hline$\sigma_{l V}$ & 0.2 & 0.132 & 0.120 & 0.150 \\
$\sigma_{l N}$ & 0.8 & 0.528 & 0.480 & 0.600 \\
$\rho_{c d V}$ & 0.057 & 0.038 & 0.034 & 0.043 \\
$\rho_{c d N}$ & 0.389 & 0.257 & 0.233 & 0.293 \\
\hline albedo & 0.232 & 0.130 & 0.1180 & 0.151 \\
\hline
\end{tabular}

the recommended values for $\sigma_{l}$ and $\rho_{c}$ (see Table 6), the predicted albedo of $23.2 \%$ is nearly double as high as the observed values of $12-14 \%$. Since radiation absorption is maximal in the visible range, the predicted albedo is much more sensitive to the selection of $\sigma_{l N}$ and $\rho_{c N}$, the scattering and reflection coefficients for near-infrared radiation, respectively (Fig. 7a). Reducing the scattering and reflection of visible radiation from 100 to $0 \%$ (from 0.2 and 0.057 to 0 for $\sigma_{l V}$ and $\rho_{c d V}$, respectively) results in a small reduction of canopy albedo $(\approx 2.1 \%)$ whereas the same scaling for nearinfrared radiation (from 0.8 and 0.389 to 0 for $\sigma_{l N}$ and $\rho_{c d N}$, respectively) reduces the albedo essentially from $23.2 \%$ to $4.3 \%$.

To minimize the large disagreement between observed and predicted canopy albedo, we have scaled leaf optical properties as listed in Table 6, although this scaling can-
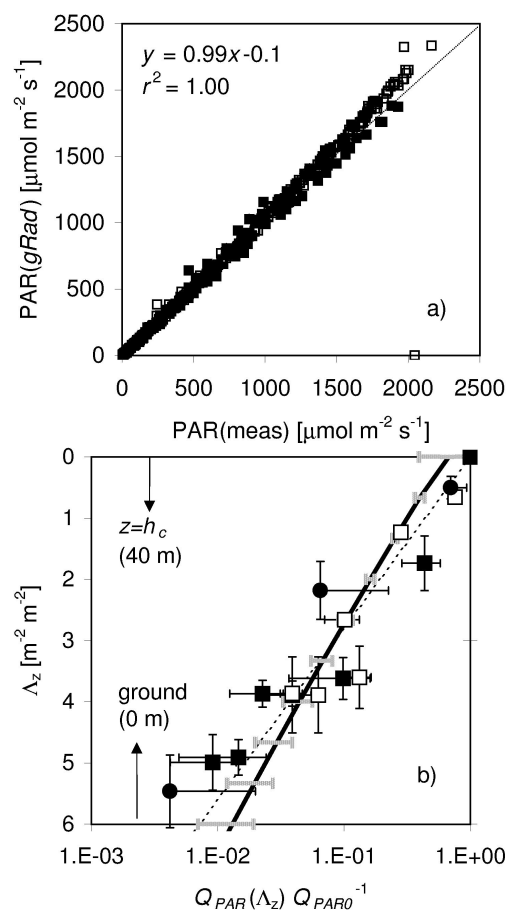

Fig. 8. (a) Incoming $\operatorname{PAR}\left(Q_{P A R 0}\right)$ derived from Eqs. (35)(36) and observed at towers RBJ-A (closed squares), RBJ-B (closed circles), and K34 (open squares). (b) Profiles of mean ratios $Q_{P A R}\left(\Lambda_{z}\right) / Q_{P A R 0}$. Observed values at towers C14 (open squares), RBJ-A in '92/'93 (closed squares) and RBJ-A in 1999 (closed circles, only positive error bars) and predictions of the two-leaf radiation absorption model constrained with observed meteorology at RBJ-A in October 1999 (solid line with standard deviations). The dotted line represents the exponential fit $y=\exp ^{-a x}, a=0.82\left(r^{2}=0.86\right)$.

not be validated due to lack of measurements. However, these findings are in agreement with the results of Wang (2003), who showed that the radiation model of Goudriaan and van Laar (1994) generally underestimates the amount of absorbed radiation. One further explanation for the poor agreement, which is obtained with non-optimized parameter values, could be the model assumption of a spherical leaf angle distribution, which is probably not fulfilled in forest ecosystems (Ross, 1981). Furthermore, in natural ecosystems, the orientation of leaves may change during the day (Jones, 1992) and optimize the ratio of absorbed to reflected canopy radiation. We assessed the significance of the parameter modifications for the CANVEG scheme in Sect. 3.7.

Equations (35-36) imply the relationship $Q_{P A R 0}=2.025$ $\mu \mathrm{mol} \mathrm{\mathbf {J } ^ { - 1 }} \mathrm{g}$ Rad which was tested by comparing measured and predicted values for a one month period (Jaru towers and K34). As shown in Fig. 8a, the observations show an excellent fit to the relationship $\left(r^{2}=1.00\right)$.

The radiation model is tested further by comparing the mean observed and predicted mean ratios 


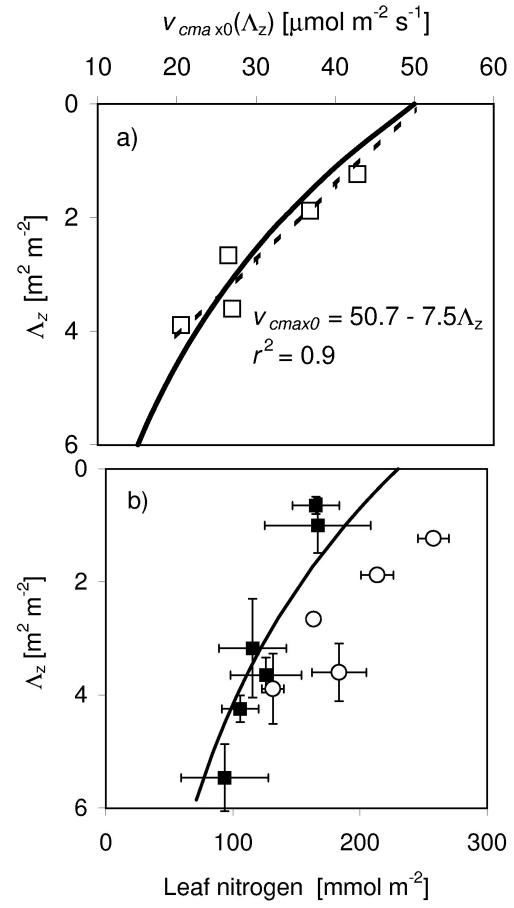

Fig. 9. (a) Relation between accumulated leaf area $\Lambda_{z}$ (see Sect. 3.1) and $v_{\operatorname{cmax} 0}$ (Carswell et al., 2000) observed at the Cuieiras site. The solid and dotted lines represent exponential $\left(k_{N}=0.2\right)$ and linear relationships, respectively. (b) Leaf nitrogen concentration $c_{N}$ at different canopy positions observed at the Cuieras site (open circles) by Carswell et al. (2000) and observed at the Jaru site (closed squares) by Lloyd et al. (1995). The determination of $\Lambda_{z}$ is described in Sect. 3.1. The solid line represents the exponential relationship $c_{N}=c_{N 0} \exp \left(-\Lambda_{z} k_{N}\right)$ with $c_{N 0}=230 \mathrm{mmol}$ $\mathrm{m}^{-2}$.

$Q_{P A R}\left(\Lambda_{z}\right) / Q_{P A R 0}$ at different canopy positions $\Lambda_{z}$ (Fig. 8b). Model results are calculated using input data from RBJ-A tower in October 1999. $Q_{P A R}\left(\Lambda_{z}\right) / Q_{P A R 0}$ is derived from the weighted sum of photosynthetic active radiation absorbed by the sunlit and shaded leaf area of a layer divided by incoming $Q_{P A R 0}$ above the canopy. A simple log-linear fit is also shown $\left(r^{2}=0.86\right)$ In general, all measurements show a similar light attenuation at lower canopy positions $\Lambda_{z}>4$. Compared to observations, the twostream radiation model predicts a lower ratio near the canopy top and a higher ratio at $\Lambda_{z} \geq 4$. Nevertheless, the agreement is reasonable considering the measurement uncertainties in $\Lambda_{z}$ and $Q_{P A R}(z)$. The simple log-linear model predicts an optimal extinction coefficient of 0.82 , which is close to the extinction coefficient for diffuse radiation and black leaves $k_{d}^{B}=0.8$ (see Leuning et al., 1995). Summarizing, the results support the assumption, that the investigated sites have a comparable canopy structure and radiation field, which can be calculated reasonably well by the two-stream radiation sub-model.
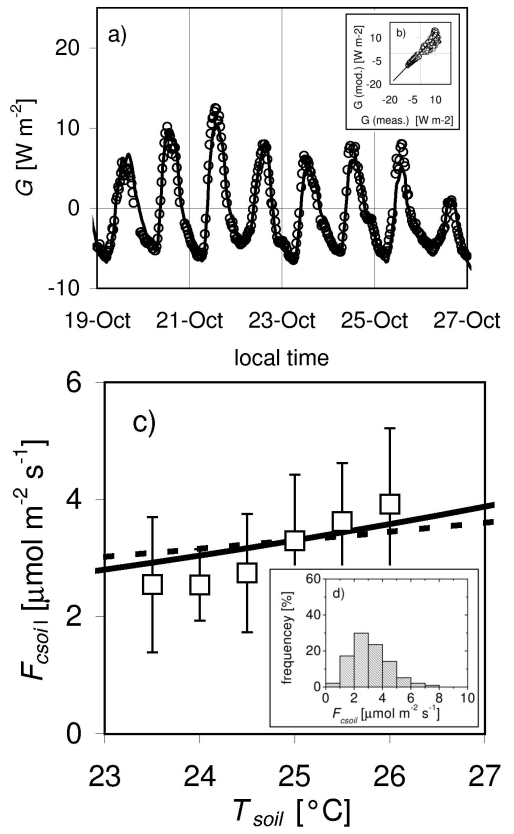

Fig. 10. (a-b) Predicted (open circles) and measured (solid line in (a) soil heat flux $(G)$ at the tower RBJ-A in 1999 using a constant bulk $(0-1 \mathrm{~m})$ soil surface conductance for heat $\left(1 / g_{\text {soil } H}=500 \mathrm{~s} \mathrm{~m}^{-1}\right)$. The linear fit shown in (b) predicts $y=1.02 x+0.92\left(r^{2}=0.92\right) . \quad(\mathbf{c}-\mathbf{d})$ Parameterization of soil respiration $\left(F_{\text {csoil }}\right)$ using continuous measurements from three soil chambers and soil temperature $\left(T_{\text {soil }}\right)$ measured at $-0.05 \mathrm{~m}$ in 1999 (dry season data from the Jaru site, RBJ-A tower, see Table 2). (c) Mean observations and standard deviations for $0.5^{\circ} \mathrm{C}$ intervals (open squares) and predictions of Eq. (30) using an optimal $Q_{10} \approx 1.6$ (dashed line) and $Q_{10} \approx 2.3$ (solid line) as derived by Meir et al. (1996) for another site. (d) Frequency distribution of $F_{\text {csoil }}$ (total $N=269$ ).

\subsection{Light acclimation of photosynthetic capacity}

A linear $v_{\text {cmax }}-c_{N}$ relationship, expressed on leaf area basis, and an exponential decrease with accumulated leaf area $\Lambda_{z}$ is applied (Eq. 32) to characterize biochemical properties of the rain forest canopy relevant for $\mathrm{CO}_{2}$ and $\mathrm{H}_{2} \mathrm{O}$ exchange (see Sect. 2.3). In Fig. 9a, $v_{\text {cmax } 0}$ observed by Carswell et al. (2000) at C14 is plotted against $\Lambda_{z}$ measured at the same tower (see Table 2). The observed light acclimation $\left(k_{N}=0.2\right)$ predicts a $70 \%$ reduction of $v_{c \max 0}$ for ground vegetation $(\mathrm{LAI}=6)$ and agrees with the shape of leaf nitrogen distribution observed by Lloyd et al. (1995) at the RBJB tower (Fig. 9b), averaged for 6 height classes (0-2, 912, 13-15, 16-21, 22-26, and 27-30 m). The correlation between $v_{\text {cmax } 0}$ and $\Lambda_{z}$ is nearly linear $\left(r^{2}=0.9\right)$. Extrapolation of the straight fitted line to the canopy top predicts $v_{\text {cmax } 0 h c} \approx 50 \mu \mathrm{mol} \mathrm{m}^{-2} \mathrm{~s}^{-1}$, which is identical to the value for tropical rain forest estimated by Wullschleger (1993) and the value for low nitrogen plants estimated by Leuning et al. 


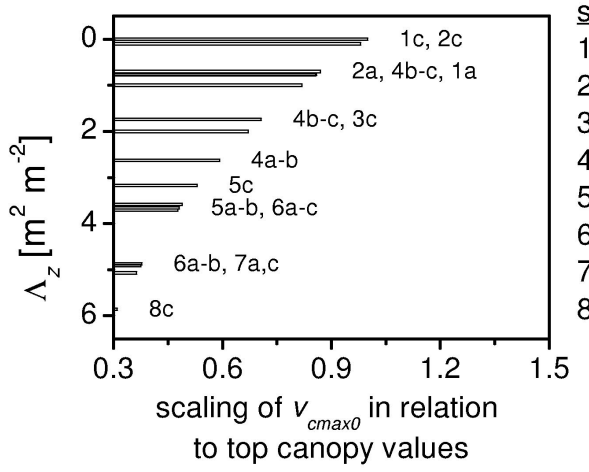

species ( $\mathrm{a}=$ wet, $\mathrm{b}=$ transitional, $\mathrm{c}=\mathrm{dry}$ season)

1a,c: Apeiba tibourbou

2a,c: Hymenaea courbaril

3c: Sorocea guilleminiana

4a-c: Cedrella odorata

5a-c: Inga spec.

6a-c: Protium polybotrium

7a,c: Leonia glycicarpa

8c: Theobroma

microcarpum

Fig. 11. Scaling of leaf physiology for the evaluation of leaf photosynthesis and stomatal model parameters using gas exchange measurements from 8 tree species made at the Jaru site. Canopy position $\left(\Lambda_{z}\right)$ and scaling of maximum carboxylation rate $\left(v_{\text {cmax } 0}\right)$ in relation to top canopy values. Measurements for species 1-8 have been made during the late wet (1-8a), early dry (1-8b) and late dry (1-8c) season. The measurement protocol for species 1-3 is described by Kuhn et al. (2002) and Kuhn et al. (2004) whereas measurements for species 4-8 are described by McWilliam et al. (1996).

(1995). Although the relationship between leaf nitrogen concentration and maximum carboxylation rate may also be expressed on a leaf mass basis (Schulze et al., 1994; Meir et al., 2002), especially when different ecosystems are compared, the relationship based on leaf area seems to be more appropriate for leaf-to-canopy scaling (Hirose and Werger, 1987; Leuning et al., 1995) in general and for undisturbed Amazon rain forest in special (Reich and Walters, 1994; Lloyd et al., 1995; Carswell et al., 2000).

\subsection{Soil surface exchange}

Measured soil heat flux $(G)$ and temperature gradients between $-0.05 \mathrm{~m}$ soil depth and $1 \mathrm{~m}$ height above the ground are used to derive the bulk soil surface conductance for heat ( $g_{\text {soil }}$, RBJ-A tower, see Table 2$)$. As shown in Figs. 10a-b, the assumption of a constant bulk conductance $1 / g_{\text {soil } H}=500 \mathrm{~s} \mathrm{~m}^{-1}$ gives a good model fit $\left(r^{2}=0.92\right)$. Typically for dense forest canopies, $G$ is relatively small $\left(<15 \mathrm{~W} \mathrm{~m}^{-2}\right)$. Figure 10 a shows a comparison of measurements and predictions for a limited period in the late dry season. Obviously, the parameterization can explain most of the observed variations of $G$.

The empirical relationship between soil respiration $\left(F_{\text {csoil }}\right)$ and temperature (Eq. 30$)$ is assessed using continuous measurements from 3 soil chambers made by Gut et al. (2002a) in October and November 1999 at the Jaru site. Figure $10 \mathrm{c}$ shows the mean values and standard deviations of $F_{\text {csoil }}$ determined for $0.5^{\circ} \mathrm{C}$ intervals. For a temperature of $25^{\circ} \mathrm{C}$, a reference respiration of $F_{\text {csoil } 0}=3.3 \mu \mathrm{mol} \mathrm{m}^{-2} \mathrm{~s}^{-1}$ is derived, which is close to the mean value of $3.13 \pm 1.3 \mu \mathrm{mol}$ $\mathrm{m}^{-2} \mathrm{~s}^{-1}$ (mean soil temperature is $24.5^{\circ} \mathrm{C}$ ). The frequency distribution of $F_{\text {csoil }}$ has a single mode (Fig. 10d). A plot of mean values against temperature intervals for classes with more than $N=10$ observations (Fig. 10c) shows a slight exponential increase within the narrow temperature range $\left(4^{\circ}\right)$.
Log-linear fitting of Eq. (30) predicts an optimal activation energy of $H_{\text {asoil }}=60 \mathrm{~kJ} \mathrm{~mol}^{-1}$ (see Sect. 2.2.4). This results in a $Q_{10}$-value of $1.6\left(Q_{10}\right.$ describes the relative increase rate of a biological process for a temperature increase of $10^{\circ} \mathrm{C}$ ), which is lower as the value of 2.3 derived by Meir et al. (1996) for another site in Amazonia. However, in the present study, this parameter uncertainty has only little effect on the uncertainty of calculated $F_{\text {csoil }}$ because the temperature range is narrow (Fig. 10c).

Soil processes have been treated as simple as possible within the present approach. For example, we can not exclude that soil moisture affects soil respiration or stomatal behavior. However there is no evidence for this in our data and these processes act on time scales that are beyond the scope of the present study. We propose to investigate feedbacks between soil and canopy processes by coupling the CANVEG scheme to a detailed soil model.

\subsection{Leaf surface exchange}

Leaf level gas exchange measurements from 8 Amazonian tree species are used to evaluate the photosynthesis and stomatal conductance models described in Sect. 2.2 and Sect. 2.2.2. Three seasonal periods are considered (late wet, early dry, and late dry season). The photosynthesis model is constrained using chamber measurements of leaf temperature, incident PAR outside the leaf chamber $\left(Q_{P A R}\right)$, and intercellular carbon dioxide concentration, calculated according to Ball (1987). The absorbed PAR radiation $\left(Q_{a b s}\right)$ is calculated as a fixed fraction of $Q_{P A R}$ assuming $Q_{a b s}=0.9 Q_{P A R}$. Vertical canopy position is estimated by combining $\Lambda_{z}$ observed at RBJ-A (see Sect. 3.1) with observed mean ratios $Q_{P A R}\left(\Lambda_{z}\right) / Q_{P A R 0}$ (species 1-3, see Fig. 8 b) or, if branch height was available, directly with $z$ (4-8). The sub-models are calibrated with parameter values recommended by Ball et al. (1987), Harley et al. (1992) 
and Leuning et al. (1995). A complete list is given in Table 4. Maximum carboxylation rates $\left(v_{\operatorname{cmax} 0}\right)$ and related parameters are scaled according to Eq. (32) using $k_{N}=0.2$ (Fig. 11, see also Sect. 3.4). The reference leaf temperature for kinetic parameters is adopted from the common value of $20^{\circ} \mathrm{C}$ (Harley et al., 1992; Leuning, 1995) to $25^{\circ} \mathrm{C}$ for tropical species (Carswell et al., 2000; Lloyd et al., 1995). Predicted optimum leaf temperature for $v_{\text {cmax }}$ and the maximum rate of electron transport $\left(J_{\max }\right)$ are 40.2 and $34.4^{\circ} \mathrm{C}$, respectively.

A comparison of the observed and predicted photosynthesis rates for late wet, early dry and late dry season conditions is shown in Figs. 12a-e. Using recommended parameter values to describe the light response and shape of the temperature dependence for the photosynthesis model leads to a large overestimation of observed $A_{n}$. The observations show a lower light use efficiency $(\alpha)$, indicated by the lower initial slope of the light response curve. Furthermore, net assimilation rates at saturating irradiance above $800 \mu \mathrm{mol} \mathrm{m}^{-2}$ $\mathrm{s}^{-1}$ are overestimated by $30-70 \%$. The measurements exhibit even a decline of $A_{n}$ at very high irradiance as observed especially for late dry season conditions. By decreasing $\alpha$ from 0.2 to 0.15 and the optimum leaf temperature for $J_{\max }$ from 34.4 to $32.6^{\circ} \mathrm{C}$, the model performs much better, indicated by the slope and intercept of the linear fits (Figs. 12ce). For the dry season data sets of species 1 and 4, the intercept value is $\approx 7 \mu \mathrm{mol} \mathrm{m}{ }^{-2} \mathrm{~s}^{-1}$ (not shown here). Obviously, photosynthesis of single species is reduced during the dry season suggesting a seasonal change of leaf physiological parameters.

Taking the measurement uncertainties and the large seasonal and species dependent variability into consideration, the model results agree reasonably well with the observations. However, the results demonstrate the high sensitivity of model predictions to the choice of individual parameter values. The optimized photosynthesis parameters are listed in Table 4.

The two stomatal models of Ball et al. (1987) and Leuning et al. (1995), hereafter referred to as B87 and L95, respectively (see Sect. 2.2.2), are very similar. For comparison, B87 and L95 are constrained using observed $A_{n}$, relative humidity $h_{s}$ (only B87) or water pressure deficit $D_{s}$ (only L95) and concentration of $\mathrm{CO}_{2}$ at the leaf surface $c_{s}$, assuming a fixed $\mathrm{CO}_{2}$ compensation point $\left(\Gamma^{*}=38.5 \mu \mathrm{mol} \mathrm{mol}{ }^{-1}\right)$. The empirical parameter expressing the sensitivity of stomatas to $D_{s}, D_{s 0}$, is set to $15 \mathrm{hPa}$ (only L95), the minimum stomatal conductance and the empirical coefficient relating $g_{s}$ to $A_{n}$ are set to $g_{s 0}=0.01 \mathrm{~mol} \mathrm{~m}^{-2} \mathrm{~s}^{-1}$ (Leuning, 1995) and $a_{A}=10$ (Ball et al., 1987; Harley et al., 1992), respectively. Since not all constraining parameters are available for the data of McWilliam et al. (1996), the analysis of $g_{s}$ is restricted to the first three species listed in Fig. $11(N=183)$. A comparison of model predictions and observations is shown in Fig. 13.
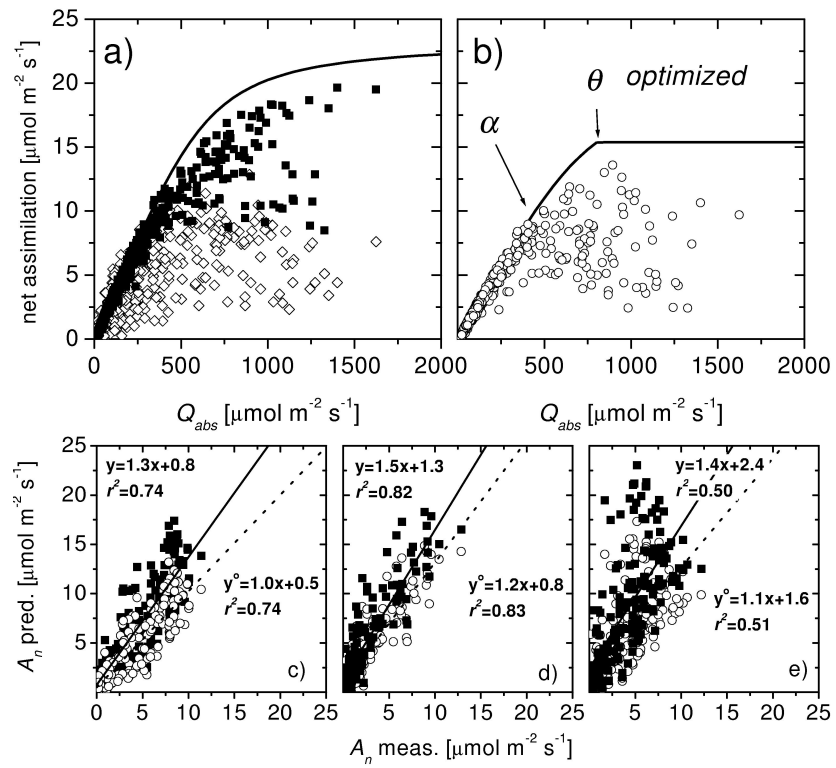

Fig. 12. (a) Comparison of observed (open diamonds) and predicted light response for the recommended parameterization (filled symbols) of the photosynthesis model. (b) Predicted light response for the optimized parameterization of the photosynthesis model (open circles). Compared to a), the quantum yield parameter $(\alpha)$, the shape parameter that determines the transition to saturation $(\theta)$ and the optimum temperature for the maximum electron transport rate $\left(J_{\max }\right)$ have been reduced. The solid lines in a,b) represent model predictions for idealized conditions $\left(v_{\text {cmax } 0}=v_{\text {cmax } 0 h c}, c_{i}=320 \mu \mathrm{mol} \mathrm{mol}^{-1}\right.$ and $\left.T_{s}=302 \mathrm{~K}\right)$. (c-e) Scatter plots and regression lines of predicted versus measured $A_{n}$ (late wet: (c); early dry: (d), late dry season: (e)) for a recommended (solid line $y$, closed symbols, see a) and optimized (dashed line $y^{o}$, open symbols, see b) model parameterization.

Both models fail to predict considerable variability observed with $g_{s}$. However, systematic deviations are small taking into consideration that model parameters $\left(g_{s 0}, a_{A}\right.$ and $D_{s 0}$ ) have not been optimized locally. The relatively poor fit for both stomatal models is to some extent in agreement with the results of Lloyd et al. (1995) who also evaluated the more detailed but purely empirical approach of Jarvis (1976), which requires many additional parameters that are usually not available. In contrast, the simple B87 and L95 models apply a simple but robust relationship between $g_{s}$ and $A_{n}$, which seems to be a reasonable description of stomatal behavior over a wide range of environmental and ecophysiological conditions.

\subsection{Model sensitivity to key parameter uncertainty}

Due to the large number of model parameters, it is practically impossible to infer the whole model parameter space. However, this is not necessary, since reliable parameter ranges have been inferred in Sects. 3.1-3.6. In the following section, 
Table 7. Assessed uncertainties of model key parameters and resulting relative change (\%) in sensible and latent heat flux and net ecosystem exchange of $\mathrm{CO}_{2}, \operatorname{var}(H)$ and $\operatorname{var}(L E)$ and $\operatorname{var}(N E E)$, respectively. The CANVEG model has been run using two mean diel cycles of micrometeorological input parameters for wet and dry season conditions, respectively, observed at the Jaru site in 1999 (a definition of symbols is given at the end see Sect. 4).

\begin{tabular}{|c|c|c|c|c|c|c|c|c|c|c|}
\hline \multirow{2}{*}{$\begin{array}{l}\text { Parameter } \\
\Lambda_{z}\end{array}$} & \multirow{2}{*}{$\frac{\text { Estimate }}{\text { mean* }}$} & \multicolumn{2}{|c|}{ Inferred range } & \multirow{2}{*}{$\begin{array}{c}\text { Reference } \\
\text { Table } 4\end{array}$} & \multicolumn{2}{|c|}{$\operatorname{var}(H)$} & \multicolumn{2}{|c|}{$\operatorname{var}(L E)$} & \multicolumn{2}{|c|}{$\operatorname{var}(N E E)$} \\
\hline & & dense $^{\dagger}$ & open $^{\ddagger}$ & & +4 & -8 & +1 & -1 & -2 & +4 \\
\hline scaling of $\rho_{c}, \sigma_{l}$ & $66 \%$ & $60 \%$ & $75 \%$ & Table 5 & -3 & +2 & -1 & +0 & -1 & +1 \\
\hline$v_{c m a x}^{1} 0 h c$ & 50 & 70 & 40 & Fig. 9 & -1 & +3 & +1 & -3 & -5 & +6 \\
\hline$k_{N}$ & 0.2 & 0.0 & 1.0 & Fig. 9 & -0 & +18 & -1 & -21 & -1 & +34 \\
\hline$\alpha, \theta$ & $0.15,0.9$ & $0.2,0.1$ & $0.95,0.8$ & Fig. 12 & -5 & +11 & +14 & -22 & -26 & +34 \\
\hline$a_{A}$ & 10 & 15 & 5 & Fig. 13 & -12 & +25 & +22 & -41 & -7 & +22 \\
\hline
\end{tabular}

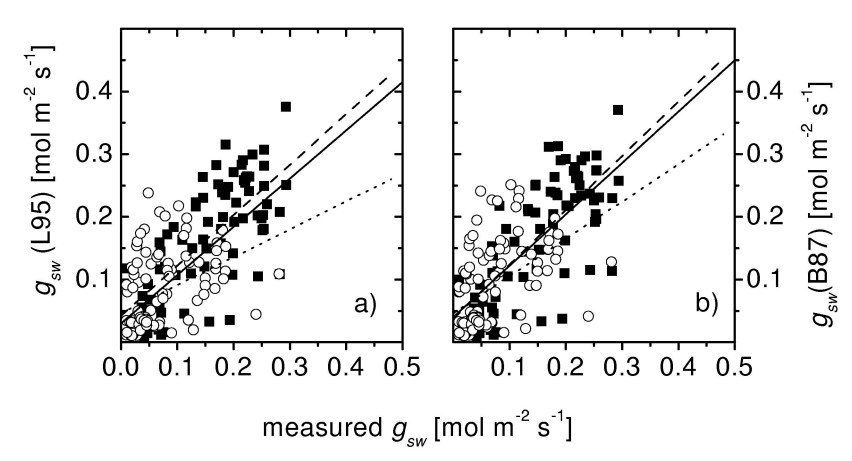

Fig. 13. Scatter plot of measured and predicted $g_{s} w$ for wet (closed squares) and dry (open circles) season conditions for (a) the L95 model (Leuning, 1995) and (b) the B87 model (Ball, 1987). Linear regression using all data (solid lines) results in: $y=0.77 x+0.03$, $r^{2}=0.51$ (L95) and $y=0.82 x+0.04, r^{2}=0.53$ (B87); Linear regression using only wet season data (dashed lines) results in: $y=$ $0.80 x+0.04, r^{2}=0.48$ (L95) and $y=0.87 x+0.04, r^{2}=0.51$ (B87); Linear regression using only dry season data (dotted lines) results in: $y=0.59 x+0.05, r^{2}=0.25$ (L95) and $y=0.45 x+0.05$, $r^{2}=0.16(\mathrm{~B} 87)$.

the sensitivity of predicted canopy net fluxes (energy and $\mathrm{CO}_{2}$ ) to the remaining parameter uncertainties is assessed. These parameters include canopy structure, the scaling of albedo parameters (leaf transmittance $\sigma_{l}$ and reflectance $\rho_{c}$ for visible and near-infrared radiation, respectively), the photosynthetic capacity of canopy top leaves $\left(v_{\text {cmax } 0 h c}\right)$ and the distributing of leaf nitrogen (light acclimation coefficient $k_{N}$ ). Additionally, seasonal changes in leaf physiology are considered by applying a model parameterization with higher stomatal conductances for wet season conditions and lower assimilation rates for dry season conditions: For wet season conditions, the parameter correlating stomatal conductance with assimilation $\left(a_{A}\right)$ is increased from 10 to 15 (see also Lloyd et al., 1995). For dry season conditions, the light use efficiency ( $\alpha$, the initial slope of light response), is reduced from 0.15 to 0.1 and the shape parameter of the hyperbolic light response function $(\theta)$ is reduced from the recommended value of 0.9 to 0.8 . The model is constrained using mean diurnal cycles of meteorological variables (Table 3) observed during the late wet and late dry season at the RBJ-A tower in Jaru in 1999. The input data is described in more detail in the companion paper (Simon et al., 2005b).

The investigated parameter ranges and the resulting model sensitivities are compiled in Table 7. Model sensitivities are calculated as the relative change of predicted sensible heat $(H)$, latent heat $(L E)$ and $\mathrm{CO}_{2}(N E E)$ canopy net fluxes. Thereby, the last six columns on the right hand side in Table 7 are derived by relating the model output, obtained with a single parameter modification (third and fourth column on the left) while keeping all others constant, to the model output obtained with the estimated parameters (Sects. 3.1-3.6).

Most relationships are nearly linear within the parameter range inferred. For canopy structure, a relatively low sensitivity of model predicted net fluxes is found. The largest variability is found for the sensible heat flux, which decreases by $12 \%$ for the open canopy compared to the dense canopy type. This may be partly explained by increased albedo (5\%) and net radiation (3\%) For the open canopy type, NEE is reduced by $5 \%$, whereas it is increased by $2 \%$ for the dense type. This is quite consistent with the derived relationship between LAI and absorbed short wave radiation $\left(Q_{a b s}\right)$, which predicts a saturation of $Q_{a b s}$ at $\mathrm{LAI} \geq 4$ (Sect. 2.3).

As discussed in Sect. 3.3, the recommended parameter values for leaf optical parameters predict a much higher canopy albedo as observed. The best fit to measurements is obtained when $\sigma_{l}$ and $\rho_{c}$ are scaled down to $60-75 \%$ of the recommended values. However, the model predicted energy fluxes are not very sensitive to the uncertainty of these parameters. The $20 \%$ variability in canopy albedo results in less than $5 \%$ variability in predicted $H$ and $L E$. Surprisingly, the sensitivity of canopy net assimilation to the photosynthetic capacity at the canopy top is relatively low. Increasing $v_{c \max 0 h c}$ by $40 \%$ increases the net $\mathrm{CO}_{2}$ uptake by only $5 \%$. For $L E$, these 

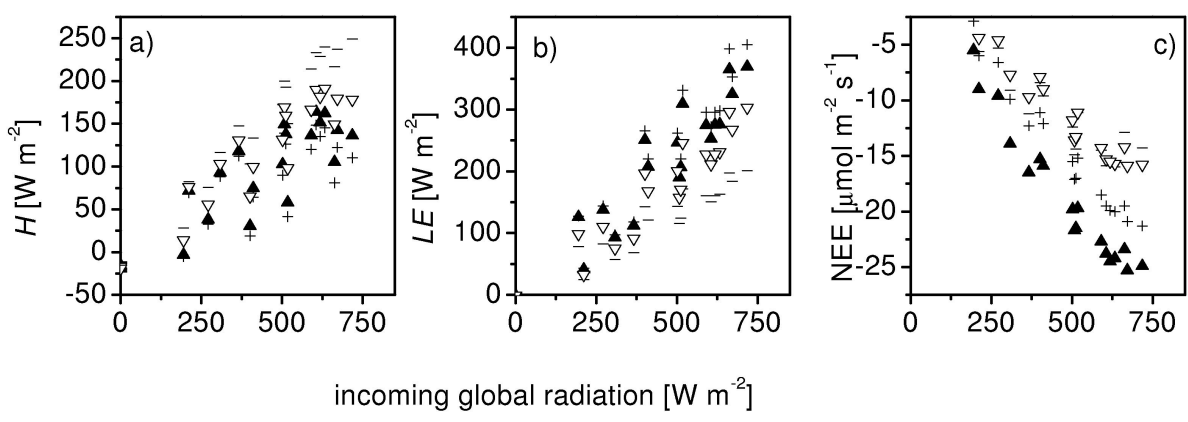

Fig. 14. Predicted canopy fluxes of sensible heat $(H)$, latent heat $(L E)$ and $\mathrm{CO}_{2}(N E E)$ plotted against incoming global radiation using an increased (+) or decreased (-) stomatal parameter $a_{A}$ (see Table 7 line 7) and increased (closed up triangle) or decreased (open down triangle) photosynthesis parameters $\alpha$ and $\theta$ (see line 5-6 in Table 7).

differences are even smaller. Obviously, the contribution of lower canopy layers to the total exchange of $L E$ and $N E E$ is low and increasing respiration of the whole foliage compensates the effect of increasing gross assimilation. The second important parameter related to canopy biochemistry is $k_{N}$, representing the extinction coefficient of photosynthetic capacity (zero value means no acclimation). In Sect. 3.4, an optimal value of 0.2 has been inferred. The flux sensitivities listed in Table 7 indicate nearly optimal distribution of leaf nitrogen since $N E E$ remains constant with decreased $k_{N}$ (which increases $v_{\text {cmax } 0}$ in the lower canopy). In contrast, increasing $k_{N}$ leads to a significant reduction of $\mathrm{CO}_{2}$ uptake $(35 \%)$.

Compared to the results described above, the predicted fluxes are much more sensitive to the physiological parameters (see Table 7). Figure 14 shows the results in more detail. The energy fluxes ( $H$ and $L E$ ) and bowen ratios $(H / L E)$ are very sensitive to the stomatal parameter $\left(a_{A}\right)$, whereas net assimilation is most sensitive to the leaf photosynthesis parameters $(\alpha, \theta)$. Reducing $a_{A}$ from 10 to 5 results in a $41 \%$ reduction of $L E$ and a $25 \%$ increase of $H$ whereas net assimilation is reduced by $22 \%$. Increasing $a_{A}$ from 10 to 15 results in a $22 \%$ increase of $L E$ and a $22 \%$ decrease of $H$. Increasing the photosynthetic parameters $(\alpha=0.2, \theta=0.95)$ leads to a nearly linear increase of absolute $N E E$ and $L E$ (26\% and $14 \%$, respectively), whereas $H$ is decreased by $5 \%$. In the opposite direction, the effect of parameter modification is even larger. Reducing the photosynthesis parameter $(\alpha=0.1, \theta=0.8)$, results in a $34 \%$ reduction of absolute $N E E$. Since $\mathrm{CO}_{2}$ is coupled to the water exchange, the partitioning of energy is also effected resulting in a strong decrease of $L E(22 \%)$ and increase $(11 \%)$ of sensible energy. These results stress the necessity of careful parameter selection and sub-model evaluation with scale appropriate data (Sect. 3.6)

\section{Conclusions}

An integrated CANVEG model scheme, describing the coupled exchange of carbon and energy between the Amazon rain forest and the lower atmosphere has been presented.

- The evaluation of calculations related to leaf photosynthesis using scale appropriate cuvette measurements made on branches and leaves of 8 tree species at different canopy positions during three seasonal periods, showed a reasonable agreement between model predictions and observations after optimization of recommended parameter values for the temperature optimum of the electron transport rate (decreased), light use efficiency (decreased), and the shape parameter describing the transition from linear to saturated light response (increased).

- The branch-level measurements indicate also a seasonal variability of leaf physiology. This is investigated in more detail within the companion paper by applying different parameterization schemes, that assume increased stomatal conductance rates for wet season conditions (by increasing the stomatal parameter $a_{A}$ from 0.15 to 0.2 ) and decreased photosynthesis rates for dry season conditions (by decreasing the light-use-efficiency $\alpha$ from 0.15 to 0.1 and the rectangular shape parameter $\theta$ from 0.9 to 0.8 , respectively).

- The sensitivity of predicted canopy net energy and $\mathrm{CO}_{2}$ fluxes to the selection of these parameters highlights the demand on ecophysiological measurements and their use and application in detailed models of surface-atmosphere exchange, as presented.

- In contrast to the large sensitivity to leaf scale parameters (5-34\%), the uncertainty of predicted canopy fluxes resulting from the uncertainty of canopy structure, i.e. total LAI, is low (1-12\%). 
- The derived distribution function for canopy structure agrees well with available observations. Site specific modifications can be achieved by changing the function scaling and shape parameters.

- An optimum number of 8 canopy layers $(\Delta z=5 \mathrm{~m})$ is derived for model application. The predicted canopy albedo is relatively insensitive to total leaf area, but strongly dependent on leaf optical parameters. Best agreement with observations is obtained when recommended values for reflectance and transmittance are reduced by $25-40 \%$.

- Also demonstrated by comparison with observations is the high accuracy of predicted PAR fractions of incoming radiation. Due to underestimation of atmospheric emissivity under high emissivity conditions, the simulated incoming long wave radiation is systematically underestimated (1-5\%), equivalent to a maximum of $25 \mathrm{~W} \mathrm{~m}^{-2}$ at noon time.

- Mean incident light observed at different sites show a similar extinction in different canopy layers when attenuation is related to vertical canopy position. A good correspondence is obtained between PAR measurements and predicted mean PAR absorbed by sunlit and shaded leaves using the canopy radiation model.

- Although the scaling of canopy biochemistry remains uncertain, available field data support the light acclimation hypothesis for Amazon rain forest. While irradiance decreases exponentially with accumulated leaf area, photosynthetic capacity was found to decrease nearly linearly.

\section{List of symbols}

$a_{i 1,2}$ coefficients in Eq. (31) with $i=T, B$ for top and bottom canopy layer, respectively (-)

$a_{A}$ empirical parameter relating stomatal conductance to assimilation (-)

$c_{p}^{m}$ specific heat of air $\left(\mathrm{J} \mathrm{mol}^{-1} \mathrm{~K}^{-1}\right)$

$c_{x} \mathrm{CO}_{2}$ concentration with subscripts soil, $i$, s, a, ref denoting the soil, intercellular, leaf surface, ambient air, and reference height level,respectively $\left(\mu \mathrm{mol} \mathrm{mol}^{-1}\right)$

$c_{N}$ leaf nitrogen concentration $\left(\mathrm{mmol} \mathrm{m}^{-2}\right)$

$d_{h}$ zero length displacement height (m)

$d(i, j)$ dispersion coefficient from layer $i$ to layer $j\left(\mathrm{~s} \mathrm{~m}^{-1}\right)$

$e$ water vapor pressure $(\mathrm{hPa})$

$f_{d, b}$ diffusive $(d)$ or direct beam $(b)$ fraction of radiation (-)
$f_{S L, S H}$ sunlit (SL) or shaded (SH) leaf fraction (-)

$g_{b}$ leaf boundary layer conductance with subscripts $H, w, c$ denoting heat, water, and $\mathrm{CO}_{2}$, and $u, f$ denoting the convective and forced part of $g_{b}$, respectively $\left(\mathrm{mol} \mathrm{m}^{-2} \mathrm{~s}^{-1}\right)$

$g_{\text {rad }}$ radiative conductance $\left(\mathrm{mol} \mathrm{m}^{-2} \mathrm{~s}^{-1}\right)$

$g_{s}$ stomatal conductance with subscripts $w$ and $c$ denoting water and $\mathrm{CO}_{2}\left(\mathrm{~mol} \mathrm{~m}^{-2} \mathrm{~s}^{-1}\right)$

$g_{\text {soilH }}$ bulk soil surface conductance for heat $\left(\mathrm{mol} \mathrm{m}^{-2} \mathrm{~s}^{-1}\right)$

$g_{t}$ total conductance with subscripts $H, w, c$ denoting heat, water, and $\mathrm{CO}_{2}\left(\mathrm{~mol} \mathrm{~m}^{-2} \mathrm{~s}^{-1}\right)$

gRad incoming global radiation with subscript 0 denoting potential global radiation $\left(\mathrm{W} \mathrm{m}^{-2}\right)$

$h_{c}$ mean canopy height $(\mathrm{m})$

$k_{d, b}^{(B)}$ extinction coefficient for diffusive $(d)$ or beam $(b)$ radiation with superscript $B$ denoting black leaves (-)

$k_{u}$ extinction coefficient for $u(-)$

$k_{N}$ extinction coefficient for $c_{N}(-)$

$n$ number of model layers (-)

$o_{i}$ intercellular oxygen concentration $\left(\mathrm{mmol} \mathrm{mol}{ }^{-1}\right)$

$s$ slope of the curve relating saturation water vapor pressure to temperature $\left(\mathrm{hPa} \mathrm{K}^{-1}\right)$

$t_{d}$ time of the year (d)

$t_{h}$ local solar time (h)

$u$ horizontal wind speed with subscript $r$ ef denoting the reference height $\left(\mathrm{m} \mathrm{s}^{-1}\right)$

$v_{\text {cmax }}$ maximum catalytic activity of Rubisco, $\left(\mu \mathrm{mol} \mathrm{m}{ }^{-2} \mathrm{~s}^{-1}\right.$, subscripts 0 and $h c$ denote $v_{\max }$ at $T_{s 0}$ and at the canopy top, respectively)

$w_{i}$ weight coefficients in Eq. (31) with $i=T$ and $i=B$ for top and bottom canopy maximum of leaf area density $(-)$

$w_{l}$ mean leaf width $(\mathrm{m})$

$z$ height above ground (m)

$z_{0}$ roughness length $(\mathrm{m})$

$z_{i}$ mean layer height $(\mathrm{m})$

$z_{i}^{*}$ upper boundary of a single leaf area distribution (m)

$z_{\text {ref }}$ reference height above $h_{c}(\mathrm{~m})$ 
$A_{n}$ net assimilation rate $\left(\mu \mathrm{mol} \mathrm{m} \mathrm{m}^{-2} \mathrm{~s}^{-1}\right)$

$A_{v}$ gross rate of photosynthesis limited by Rubisco activity $\left(\mu \mathrm{mol} \mathrm{m} \mathrm{s}^{-2}\right)$

$A_{J}$ gross rate of photosynthesis limited by $\mathrm{RuP}_{2}$ regeneration $\left(\mu \mathrm{mol} \mathrm{m} \mathrm{m}^{-2} \mathrm{~s}^{-1}\right)$

$C_{x}$ scalar concentration with subscripts $i, s, a$, ref denoting the leaf intercellular space, leaf surface, ambient air, and reference height level, respectively

$D_{s 0}$ empirical coefficient reflecting the stomatal sensitivity to $D_{s}(\mathrm{hPa})$

$D_{x}$ water vapor pressure deficit with subscripts soil,i,s,a,ref denoting the soil, intercellular, leaf surface, ambient air, and reference height level, respectively $(\mathrm{hPa})$

$E$ leaf transpiration $\left(\mathrm{mmol} \mathrm{m} \mathrm{m}^{-2} \mathrm{~s}^{-1}\right)$

$F$ trace gas flux expressed on ground area

$F_{\text {csoil }}$ soil respiration with subscript 0 denoting $F_{\text {csoil }}$ at $T_{\text {soil }}$ $\left(\mu \mathrm{mol} \mathrm{m} \mathrm{m}^{-2} \mathrm{~s}^{-1}\right)$

$F_{\text {leaf }}$ trace gas flux expressed on leaf area

$G$ soil heat flux $\left(\mathrm{W} \mathrm{m}^{-2}\right)$

Gr Grashof number (-)

$H$ sensible heat flux $\left(\mathrm{W} \mathrm{m}^{-2}\right)$

$H_{x}$ energy with subscripts $d$ and $v$ and $K o, K c, R d, V, J$, and soil denoting the activation and deactivation of $K_{c}, K_{o}, R_{d}, v_{\text {cmax }}, J_{\text {max }}$, and $F_{\text {csoil }}$, respectively (J $\mathrm{mol}^{-1}$ )

$I_{x}$ the incomplete beta function

$J$ electron transport rate $\left(\mu \mathrm{mol} \mathrm{m}{ }^{-2} \mathrm{~s}^{-1}\right)$

$J_{\max }$ potential rate of electron transport with subscript 0 denoting $J_{\max }$ at $T_{s 0}\left(\mu \mathrm{mol} \mathrm{m}{ }^{-2} \mathrm{~s}^{-1}\right)$

$K_{c, o}$ Michaelis coefficient with subscripts $c$ and $o$ denoting for carboxylation and oxygenation, respectively ( $\mu \mathrm{mol}$ $\left.\mathrm{m}^{-2} \mathrm{~s}^{-1}\right)$

$L_{s}$ canopy length scale (m)

$L E$ canopy latent heat flux $\left(\mathrm{W} \mathrm{m}^{-2}\right)$

$N E E$ net ecosystem exchange of $\mathrm{CO}_{2}\left(\mu \mathrm{mol} \mathrm{m}{ }^{-2} \mathrm{~s}^{-1}\right)$

$P_{0}$ air pressure at the reference height $(\mathrm{hPa})$

$Q_{10}$ change rate of a biological process for a temperature increase of $10^{\circ} \mathrm{C} \mathrm{(-)}$
$Q_{d, b, s b}$ diffusive $(d)$, direct beam $(b)$ or scattered $(s b)$ beam radiation. Subscript 0 indicates incoming radiation. (W $\mathrm{m}^{-2}$ )

$Q_{n}$ net radiation $\left(\mathrm{W} \mathrm{m}{ }^{-2}\right)$

$Q_{n}^{*}$ isothermal net radiation assuming $T_{s}=T_{a}\left(\mathrm{~W} \mathrm{~m}^{-2}\right)$

$Q_{L W}$ long wave radiation. Subscript 0 indicates incoming radiation $\left(\mathrm{W} \mathrm{m}^{-2}\right)$

$Q_{N, V}$ visible $(V)$ or near-infrared $(N)$ radiation. Subscript 0 indicates incoming radiation $\left(\mathrm{W} \mathrm{m}^{-2}\right)$

$Q_{P A R}$ photosynthetic active radiation. Subscript 0 indicates incoming radiation $\left(\mu \mathrm{mol} \mathrm{m} \mathrm{m}^{-2} \mathrm{~s}^{-1}\right)$

$Q_{S H, S L}$ radiation absorbed by sunlit $(S L)$ or shaded $(S H)$ leaves $\left(\mathrm{W} \mathrm{m}^{-2}\right)$

$Q_{S W}$ short-wave radiation. Subscript 0 indicates incoming radiation $\left(\mathrm{W} \mathrm{m}^{-2}\right)$

$R$ universal gas constant $\left(8.3145 \mathrm{~J} \mathrm{~mol}^{-1} \mathrm{~K}^{-1}\right)$

$R_{d}$ day respiration $\left(\mu \mathrm{mol} \mathrm{m} \mathrm{m}^{-2} \mathrm{~s}^{-1}\right)$

$R H_{x}$ relative humidity with subscripts soil, $i, s, a$, ref denoting the soil, intercellular, leaf surface, ambient air, and reference height level, respectively (-)

$S_{i}$ source/sink strength of layer $i$

$S_{v, d}$ entropy for activation $(v)$ and deactivation $(d)\left(\mathrm{J} \mathrm{mol}^{-1}\right)$

$T_{x} \quad$ temperature with subscripts soil, $s, a, r$ ef denoting the soil, leaf surface, ambient air, and reference height level, respectively $(\mathrm{K})$

$T_{x 0}$ reference temperature $(\mathrm{K})$

$\alpha$ quantum yield of whole-chain electron transport (-)

$\gamma_{0,1,2}$ empirical constants required to calculate $\Gamma_{*}(-)$

$\gamma_{\text {air }}$ psychometric constant $\left(\mathrm{hPa} \mathrm{K}^{-1}\right)$

$\epsilon_{a 0, s}$ long-wave emissivity with subscripts $a 0$ and $s$ denoting the atmosphere and surface (leaves and soil), respectively (-)

$\eta_{w}, \eta_{w}^{*}$ water filled soil pore space, total soil pore space (-)

$\theta$ shape coefficient of the hyperbolic light response function for photosynthesis (-)

$\lambda^{m}$ latent heat of vaporization for water $\left(\mathrm{J} \mathrm{mol}^{-1}\right)$

$\lambda^{C}$ chemical energy stored by $\mathrm{CO}_{2}$ fixation $\left(\mathrm{J} \mu \mathrm{mol}^{-1}\right)$

$\rho_{c x}$ canopy reflection coefficient with subscripts $x=d, b$ and $N, V$ denoting diffusive or beam, and visible or nearinfrared radiation, respectively $(-)$ 
$\rho_{h}$ canopy reflection coefficient for horizontal leaves (-)

$\sigma_{l x}$ scattering coefficient with subscripts $x=d, b$ and $N, V$ denoting diffusive or beam, and visible or near-infrared radiation, respectively $(-)$

$\sigma_{B}$ Stefan-Boltzmann constant $\left(5.67051 \times 10^{-8}\right)\left(\mathrm{W} \mathrm{m}^{-2}\right.$ $\mathrm{K}^{-4}$ )

$\psi_{\text {soil }}$ soil matrix potential with superscript $*$ denoting maximum $\psi_{\text {soil }}(-)$

$\Gamma \mathrm{CO}_{2}$ compensation point $\left(\mu \mathrm{mol} \mathrm{mol}^{-1}\right)$

$\Gamma_{*} \mathrm{CO}_{2}$ compensation point in the absence of day respiration $\left(\mu \mathrm{mol} \mathrm{mol}^{-1}\right)$

$\Lambda_{0, z, h c}$ accumulated leaf area with subscripts $0, z, h c$ denoting total LAI, at height $z$ and (zero) at the canopy top $\left(\mathrm{m}^{2}\right.$ $\mathrm{m}^{-2}$ )

Acknowledgements. We would like to thank many people for providing high quality field data from Amazonia, especially U. Rummel, U. Kuhn, S. Rottenberger, C. Ammann, A. Gut, G. Kirkman (MPIC), B. Kruijt and J. Elbers (Alterra-Institute), J. Lloyd (University of Leeds) and representatively for the pre-LBA studies the UK Institute of Hydrology for making the ABRACOS data sets available. The research is supported by the Max Planck Society and the European Union (EUSTACH-LBA; ENV4-CT970566).

Edited by: A. Goldstein

\section{References}

Andreae, M. O., Artaxo, P., Brandao, C., Carswell, F. E., Ciccioli, P., da Costa, A. L., Culf, A. D., Esteves, J. L., Gash, J. H. C., Grace, J., Kabat, P., Lelieveld, J., Malhi, Y., Manzi, A. O., Meixner, F. X., Nobre, A. D., Nobre, C., Ruivo, M., Silva-Dias, M. A., Stefani, P., Valentini, R., von Jouanne, J., and Waterloo, M. J.: Biogeochemical cycling of carbon, water, energy, trace gases, and aerosols in Amazonia: The LBA-EUSTACH experiments, J. Geophys. Res., 107, 33.1-33.25, 2002.

Araujo, A., Nobre, A., Kruijt, B., Elbers, J., Dallarosa, R., Stefani, P., von Randow, C., Manzi, A., Culf, A., Gash, J., Valentini, R., and Kabat, P.: Comparative measurements of carbon dioxide fluxes from two nearby towers in a central Amazonian rainforest: The Manaus LBA site, J. Geophys. Res., 107, 58.1-58.20, 2002.

Baldocchi, D.: A Lagrangian random-walk model for simulating water vapour, $\mathrm{CO}_{2}$ and sensible heat flux densities and scalar profiles over and within a soybean canopy, Bound.-Layer Meteorol., 61, 113-144, 1992.

Baldocchi, D. and Bowling, D. R.: Modelling the discrimination of ${ }^{13} \mathrm{CO}_{2}$ above and within a temperate broad-leaved forest canopy on hourly to seasonal timescales, Plant, Cell Env., 26, 231-244, 2003.

Baldocchi, D. and Harley, P.: Scaling carbon dioxide and water vapour exchange from leaf to canopy in a deciduous forest: Model testing and application, Plant, Cell Env., 18, 1157-1173, 1995.
Baldocchi, D. and Meyers, T.: On using eco-physiological, micrometeorological and biogeochemical theory to evaluate carbon dioxide, water vapor and trace gas fluxes over vegetation - a perspective, Agric. For. Meteorol., 90, 1-25, 1998.

Baldocchi, D. D. and Wilson, K. B.: Modeling $\mathrm{CO}_{2}$ and water vapor exchange of a temperate broadleaved forest across hourly to decadal time scales, Ecol. Model., 142, 155-184, review, 2001.

Ball, J.: Calculations related to gas exchange, in Stomatal Function, edited by: Zeiger, E., Farquhar, G., and Cowan, I., Stanford University Press, Stanford, California, 445-476, 1987.

Ball, J., Woodrow, I., and Berry, J.: A model predicting stomatal conductance and its contribution to the control of photosynthesis under different environmental conditions, in: Progress in Photosynthesis Research, edited by: Biggins, I., Martinus Nijhoff, Netherlands, 221-224, 1987.

Brutsaert, W.: On a derivable formula for long-wave radiation for clear skies, Water Resources Res., 11, 742-744, 1975.

Caemmerer, S. v. and Farquhar, G. D.: Some relationships between the biochemistry of photosynthesis and the gas exchange of leaves, Planta, 153, 376-387, 1981.

Carswell, F., Meir, P., Wandell, E., Bonates, L., Kruijt, B., Barbosa, E., Nobre, A., Grace, J., and Jarvis, P.: Photosynthetic capacity in a central Amazonian rain forest, Tree Physiol., 20, 179-186, 2000.

Collatz, G., Ball, J., Grivet, C., and Berrry, J.: Phyiosiological and environmental regulation of stomatal conductance, photosynthesis and transpiration: A model that includes a laminar boundary layer, Agric. For. Meteorol., 54, 107-136, 1991.

Collatz, G., Ribbas-Carbo, M., and Berry, J.: Coupled photosynthesis-stomatal conductance model for leaves of $\mathrm{C} 4$ plants, Aust. J. Plant Physiol., 54, 107-136, 1992.

Culf, A., Fisch, G., and Hodnett, M.: The albedo of Amazonian forest ranch land, J. Climate, 8, 1543-1554, 1995.

Culf, A., Esteves, J. L., Filho, M. O., and Rocha, H. d.: Radiation, temperature and humidity over forest and pasture in Amazonia, in Amazonian Deforestation and Climate, edited by: Gash, J., Nobre, C., Roberts, J., and Victoria, R., John Wiley and Sons, Chichester, 177-191, 1996.

Deardorff, J.: Efficient prediction of ground surface temperature and moisture with inclusion of a layer of vegetation, J. Geophys. Res., 83, 1889-1903, 1978.

Dickinson, R. E., Henderson-Sellers, A., and Kennedy, P. J.: Biosphere-Atmosphere Transfer Scheme (BATS) version 1e as coupled to the NCAR community climate model, NCAR Technical Note 387, NCAR, 1993.

Eschenbach, C. and Kappen, L.: Leaf area index determination in an alder forest - a comparison of three methods, Journal of Experimental Botany, 47, 1457-1462, 1996.

Evans, J.: Photosynthesis and nitrogen relationships in leaves of C3 plants, Oecologia, 78, 9-19, 1989.

Falge, E., Baldocchi, D., Tenhunen, J., Aubinet, M., Bakwin, P., Berbigier, P., Bernhofer, C., Burba, G., Clement, R., Davis, K. J., Elbers, J. A., Goldstein, A. H., Grelle, A., Granier, A., Guomundsson, J., Hollinger, D., Kowalski, A. S., Katul, G., Law, B. E., Malhi, Y., Meyers, T., Monson, R. K., Munger, J. W., Oechel, W., Paw U, K. T., et al.: Seasonality of ecosystem respiration and gross primary production as derived from FLUXNET measurements, Agric. For. Meteorol., 113, 53-74, 2002.

Farquhar, G. D., Caemmerer, S. v., and Berry, J.: A biochemi- 
cal model of photosynthetic $\mathrm{CO}_{2}$ assimilation in leaves of $\mathrm{C}_{3}$ species, Planta, 149, 78-90, 1980.

Field, C.: Allocating leaf nitrogen for the maximization of carbon gain: leaf age as a control on the allocation program, Oecologia, 56, 341-347, 1983.

Field, C. and Mooney, H.: The photosynthesis-nitrogen relationship in wild plants, in On the Economy of Plant Form and Function, edited by: Givnish, T., Cambridge University Press, 25-55, 1986.

Ganzeveld, L. and Lelieveld, J.: Dry deposition parameterization in a chemistry general circulation model and its influence on the distribution of reactive trace gases, J. Geophys. Res., 100, 20 999-21 012, 1995.

Garrat, J.: The Atmospheric Boundary Layer, Cambridge Atmospheric and Space Science Series, Cambridge University Press, Cambridge, 1992.

Gash, J., Nobre, C., Roberts, J., and Victoria, R.: An overview of ABRACOS, in Amazonian Deforestation and Climate, edited by: Gash, J., Nobre, C., Roberts, J., and Victoria, R., John Wiley and Sons, Chichester, 1-14, 1996.

Goudriaan, J. and van Laar, H.: Modelling Crop Growth Processes, Kluwer, Amsterdam, 1994.

Grace, J., Lloyd, J., McIntyre, J., Miranda, A., Meir, P., Miranda, H., Moncrieff, J., Massheder, J., Wright, I., and Gash, J.: Fluxes of carbon dioxide and water vapour over an undisturbed tropical rain forest in south-west Amazonia, Glob. Clim. Change, 1, 1$12,1995$.

Gu, L. H. and Baldocchi, D.: Fluxnet 2000 synthesis - foreword, Agric. For. Meteorol., 113, 1-2, 2002.

Gut, A., Scheibe, M., Rottenberger, S., Rummel, U., Welling, M., Ammann, C., Kirkman, G., Kuhn, U., Meixner, F., Kesselmeier, J., Lehmann, B., Schmidt, J., Müller, E., and Piedade, M.: Exchange of $\mathrm{NO}_{2}$ and $\mathrm{O}_{3}$ at soil and leaf surfaces in an Amazonian rain forest, J. Geophys. Res., 107, 27.1-27.15, 2002a.

Gut, A., van Dijk, S., Scheibe, M., Rummel, U., Welling, M., Ammann, C., Meixner, F., Kirkman, G., Andreae, M., and Lehmann, B.: NO emission from an Amazonian rain forest soil: Continous measurements of NO flux and soil concentration, J. Geophys. Res., 102, 24.1-24.10, 2002b.

Halldin, S., Bergstrom, H., Gustafsson, D., Dahlgren, L., Hjelm, P., Lundin, L. C., Mellander, P. E., Nord, T., Jansson, P. E., Seibert, J., Stahli, M., Kishne, A. S., and Smedman, A. S.: Continuous long-term measurements of soil-plant-atmosphere variables at an agricultural site, Agric. For. Meteorol., 98-9, 75-102, 1999.

Harley, P., Thomas, R., Reynolds, J., and Strain, B.: Modelling photosynthesis of cotton grown in elevated $\mathrm{CO}_{2}$, Plant, Cell Env., 15, 1992.

Hirose, T. and Bazzaz, F. A.: Trade-off between light- and nitrogenuse efficiency in canopy photosynthesis, Ann. Bot., 82, 195-202, 1998.

Hirose, T. and Werger, M.: Nitrogen use efficiency in instantaneous and daily photosynthesis of leaves in the canopy of a Solidago altissima stand, Physiolog. Plant., 70, 215-222, 1987.

Hirose, T., Werger, M., Pons, T., and Rheenen, J. v.: Canopy structure and leaf nitrogen distribution in a stand of Lysimachia vulgaris $L$. as influenced by stand density, Oecologia, 77, 1988.

Jarvis, P.: Scaling physiological processes, in Scaling Physiological Processes Leaf to Globe, edited by Ehleringer, J. R. and Field, C. B., Academic Press, San Diego - London, 115-126, 1993.
Jarvis, P. G.: The interpretation of variations in leaf water potential and stomatal conductance found in canopies in the field, Phil. Trans. Roy. Soc. B, 273, 593-610, 1976.

Jones, H.: Plants and Microclimate: A Quantitative Approach to Plant Physiology, Cambridge University Press, Cambridge, 1992.

Kaimal, J. and Finnigan, J.: Atmospheric Boundary Layer Flows, Oxford University Press, New York, 1994.

Katul, G., Leuning, R., and Oren, R.: Relationship between plant hydraulic and biochemical properties derived from a steady-state coupled water and carbon transport model, Plant Cell Env., 26, 339-350, 2003.

Katul, G. G. and Albertson, J. D.: Modeling $\mathrm{CO}_{2}$ sources, sinks, and fluxes within a forest canopy, J. Geophys. Res., 104, 60816091, 1999.

Klinge, H.: Struktur und Artenreichtum des zentralamazonischen Regenwaldes, Amazoniana, 4, 283-292, 1973.

Klinge, H., Rodriques, W., Brunig, E., and Fittkau, E.: Biomass and structure in a central Amazonian rain forest, in Tropical Ecological Systems. Trends in Terrestrial and Aquatic Research, edited by: Golley, F. and Medina, E., Springer, Berlin, 115-122, 1975.

Kruijt, B., Malhi, Y., Lloyd, J., Nobre, A., Miranda, A., Pereira, M., Culf, A., and Grace, J.: Turbulence statistics above and within two Amazon rain forest canopies, Bound.-Layer Meteorol., 94, 297-331, 2000.

Kuhn, U., Rottenberger, S., Biesenthal, T., Ammann, C., Wolf, A., Schebeske, G., Ciccioli, P., Branaleoni, E., Frattoni, M., Tavares, T., and Kesselmeier, J.: Isoprene and monoterpene emissions of Amazonian tree species during the wet season: Direct and indirect investigations on controlling environmental functions, J. Geophys. Res., 107, 38.1-38.13, 2002.

Kuhn, U., Rottenberger, S., Biesenthal, T., Wolf, A., Schebeske, G., Ciccioli, P., Branaleoni, E., Frattoni, M., Tavares, T., and Kesselmeier, J.: Seasonal differences in isoprene and lightdependent monoterpene emission by Amazonian tree species, Global Change Biol., 10, 663-682, 2004.

Lai, C. T., Katul, G., Ellsworth, D., and Oren, R.: Modelling vegetation-atmosphere $\mathrm{CO}_{2}$ exchange by a coupled EulerianLagrangian approach, Bound.-Layer Meteorol., 95, 91-122, 2000a.

Lai, C. T., Katul, G., Oren, R., Ellsworth, D., and Schfer, K.: Modelling $\mathrm{CO}_{2}$ and water vapor turbulent flux distributions within a forest canopy, J. Geophys. Res., 105, 26333-26 351, $2000 \mathrm{~b}$.

Laurance, W. F.: Mega-development trends in the Amazon: Implications for global change, Env. Monit. Assessment, 61, 113-122, 2000.

Leuning, R.: Modelling stomatal behaviour and photosynthesis of Eucalyptus grandis, Aust. J. Plant Physiol., 17, 159-175, 1990.

Leuning, R.: A critical appraisal of a combined stomatalphotosynthesis model for $\mathrm{C}_{3}$ plants, Plant, Cell Env., 18, 339357, 1995.

Leuning, R., Kelliher, F. M., de Pury, D. G. G., and Schulze, E. D.: Leaf nitrogen, photosynthesis, conductance and transpiration: scaling from leaves to canopies, Plant, Cell Env., 18, 1183-1200, 1995.

Lloyd: Modelling stomatal responses to environment in Macadamia integrifolia, Aust. J. Plant Physiol., 18, 649-660, 1991.

Lloyd, J., Grace, J., Miranda, A. C., Meir, P., Wong, S. C., Miranda, B. S., Wright, I. R., Gash, J. H. C., and McIntyre, J.: A simple 
calibrated model of amazon rainforest productivity based on leaf biochemical properties, Plant, Cell Env., 18, 1129-1145, 1995.

Lohammer, T., Larsson, S., Linder, S., and Falk, S.: FAST - simulation models of gaseous exchange in Scots Pine, Ecol. Bull., 32, 1980.

McNaughton, H.: Effective stomatal boundary-layer resistances of heterogenous surfaces, Plant, Cell Env., 17, 1061-1068, 1994.

McWilliam, A.-L., Roberts, J., Cabral, O., Leitao, M., Costa, A. d., Maitelli, G., and Zamparoni, C.: Leaf area index and aboveground biomass of terra firme rain forest and adjecent clearings in Amazonia, Funct. Ecol., 7, 310-317, 1993.

McWilliam, A.-L., Cabral, O. M. R., Gomes, B., Esteves, J. L., and Roberts, J.: Forest and pasture leaf-gas exchange in south-west Amazonia, in Amazonian Deforestation and Climate, edited by Gash, J., Nobre, C., Robers, J., and Victoria, R., John Wiley, Chichester, 265-285, 1996.

Meir, P., Grace, J., Miranda, A., and LLoyd, J.: Soil respiration in a rainforest in Amazonia and in cerrado in central Brazil, in Amazonian Deforestation and Climate, edited by Gash, J., Nobre, C., Robers, J., and Victoria, R., John Wiley, Chichester, 319-329, 1996.

Meir, P., Kruijt, B., Broadmeadow, M., Barbosa, E., Kull, O., Carswell, F., Nobre, A., and Jarvis, P. G.: Acclimation of photosynthetic capacity to irradiance in tree canopies in relation to leaf nitrogen concentration and leaf mass per unit area, Plant, Cell Env., 25, 343-357, 2002.

Meyers, T. and Paw U, K.: Testing of a higher-order closure model for modeling airflow within and above plant canopies, Bound.Layer Meteorol., 37, 297-311, 1986.

Monteith, J.: Evaporation and environment, Sym. Soc. Exp. Biol., 19, 206-234, 1965.

Monteith, J.: Principles of Environmental Physics, Edward Arnold, London, 1973.

Niinemets, U., Tenhunen, J. D., Canta, N. R., Chaves, M. M., Faria, T., Pereira, J. S., Reynolds, J. F., 1999. Interactive effects of nitrogen and phosphorus on the acclimation potential of foliage photosynthetic properties of cork oak, Quercus suber, to elevated atmospheric $\mathrm{CO}_{2}$ concentrations. Global Change Biol. 5 (4), 455-470, 1999.

Noilhan, J. and Planton, S.: A simple parameterization of land surface processes for meteorological models, Mon. Weather Rev., 117, 536-549, 1989.

Norman, J. and Welles, J.: Radiative transfer in an array of canopies, Agron. J., 75, 481-488, 1983.

Press, W. H.: Numerical Recipes in C: the Art of Scientific Computing., Vol. 1, University press, Cambridge, 2 edn., 1997.

Raupach, M. R.: A Lagrangian analysis of scalar transfer in vegetation canopies, Q. Roy. S. Meteor. Soc., 113, 107-120, 1987.

Raupach, M. R.: A practical Lagrangian method for relating scalar concentrations to source distributions in vegetation canopies, Q. J. R. Met. Soc., 115, 609-632, 1989.

Reich, P. and Walters, M.: Photosynthesis-nitrogen relations in Amazonian tree species, Oecologia, 97, 73-81, 1994.

Ribeiro, J. d. S., Hopkins, M., Vicentini, A., Sothers, C., Costa, M. d. S., Brito, J. d., Souza, M. d., Martins, L., Lohmann, L., Assuncao, P., Pereira, E. d. C., Silva, C. d., Mesquita, M., and Procopio, L.: Flora da Reserva Ducke: Guia de identificacao das plantas vasculares de uma floresta de terra-firme na Amazonia Central, INPA, Manaus, 1999.
Roberts, J., Cabral Osvaldo, M. R., Fisch, G., Molion, L. C. B., Moore, C. J., and Shuttleworth, W. J.: Transpiration from an Amazonian rainforest calculated from stomatal conductance measurements, Agric. For. Meteorol., 65, 175-196, 1993.

Ross, J.: The Radiation Regime and Architecture of Plant Stands, Dr. W. Junk, Norwell, MA, 1981.

Rummel, U.: Turbulent exchange of ozone and nitrogen oxides from a tropical rain forest in Amazonia, Phd thesis, University Bayreuth, Germany, 2005.

Rummel, U., Ammann, C., Gut, A., Meixner, F., and Andreae, M.: Eddy covariance measurements of nitric oxide flux within an Amazonian rain forest, J. Geophys. Res., 107, 17.1-17.9, 2002.

Schulze, E.-D., Kelliher, F., Körner, C., Lloyd, J., and Leuning, R.: Relationship between maximum stomatal conductance, ecosystem surface conductance, carbon assimilation and plant nitrogen nutrition: A global ecology scaling exercise, Annu. Rev. Ecol. Syst., 25, 629-660, 1994.

Sellers, P., Berry, J., Collatz, G., Field, C., and Hall, F.: Canopy reflectance, photosynthesis and transpiration. III: A reanalysis using improved leaf models and a new canopy integration scheme, Remote Sens. Environ., 42, 187-216, 1992.

Sellers, P., Randall, D., Collatz, G., Berry, J., Field, C., Dazlich, D., Zhang, C., Collello, G., and Bounoua, L.: A revised land surface parameterization (SIB2) for Atmospheric GCMs. Part I: Model formulation, J. Climate, 9, 676-705, 1996.

Sellers, P. J., Hall, F. G., Kelly, R. D., Black, A., Baldocchi, D., Berry, J., Ryan, M., Ranson, K. J., Crill, P. M., Lettenmaier, D. P., Margolis, H., Cihlar, J., Newcomer, J., Fitzjarrald, D., Jarvis, P. G., Gower, S. T., Halliwell, D., Williams, D., Goodison, B., Wickland, D. E., and Guertin, F. E.: Boreas in 1997 experiment overview, scientific results, and future directions, J. Geophys. Res., 102, 28 731-28 769, 1997.

Seufert, G., Bartzis, J., Bomboi, T., Ciccioli, P., Cieslik, S., Dlugi, R., Foster, P., Hewitt, C. N., Kesselmeier, J., Kotzias, D., Lenz, R., Manes, F., Pastor, R. P., Steinbrecher, R., Torres, L., Valentini, R., and Versino, B.: An overview of the Castelporziano experiments, Atmos. Environ., 31, 5-17, 1997.

Simon, E., Lehmann, B., Ammann, C., Ganzeveld, L., Rummel, U., Nobre, A., Araujo, A., Meixner, F., Kesselmeier, J.: Lagrangian dispersion of ${ }^{222} \mathrm{Rn}, \mathrm{H}_{2} \mathrm{O}$ and $\mathrm{CO}_{2}$ within Amazon rain forest, Agric. For. Meteorol., accepted, 2005a.

Simon, E., Meixner, F., Rummel, U., Ganzeveld, L., Ammann, C., Kesselmeier, J.: Coupled carbon-water exchange of the Amazon rain forest, II. Comparison of predicted and observed seasonal exchange of energy, $\mathrm{CO}_{2}$, isoprene and ozone at a remote site in Rondônia, Biogeosciences Discuss., 2, 399-445, 2005b,

SRef-ID: 1810-6285/bgd/2005-2-399.

Splitters, C.: Separating the diffusive and direct component of global radiation and its implications for modelling canopy photosynthesis, part II: Calculation of canopy photosynthesis, Agric. For. Meteorol., 38, 231-242, 1986.

Tuzet, A., Perrier, A., and Leuning, R.: A coupled model of stomatal conductance, photosynthesis and transpiration, Plant, Cell Env., 26, 1097-1116, 2003.

Walters, M. and Field, C.: Photosynthetic light acclimation in two rainforest Piper species with different ecological amplitudes, Oecologia, 72, 449-456, 1987.

Wang, Y.: A comparison of three different canopy radiation models commonly used in plant modelling, Funct. Plant Biol., 30, 143- 
152, 2003.

Wang, Y.-P. and Leuning, R.: A two-leaf model for canopy conductance, photosynthesis and partitioning of available energy I: Model description and comparison with a multi-layered model, Agric. For. Meteorol., 91, 89-111, 1998.

Williams, M., Malhi, Y., Nobre, A. D., Rastetter, E. B., Grace, J., and Pereira, M. G. P.: Seasonal variation in net carbon exchange and evapotranspiration in a Brazilian rain forest: a modelling analysis, Plant, Cell Env., 21, 953-968, 1998.
Wilson, T. B., Norman, J. M., Bland, W. L., and Kucharik, C. J.: Evaluation of the importance of Lagrangian canopy turbulence formulations in a soil-plant-atmosphere model, Agric. For. Meteorol., 115, 51-69, 2003.

Wullschleger, S.: Biochemical limitations to carbon assimilation in $\mathrm{C}_{3}$ plants $-\mathrm{A}$ retrospective analysis of the $A / c_{i}$ curves from 109 species, J. Exp. Bot., 44, 907-920, 1993. 